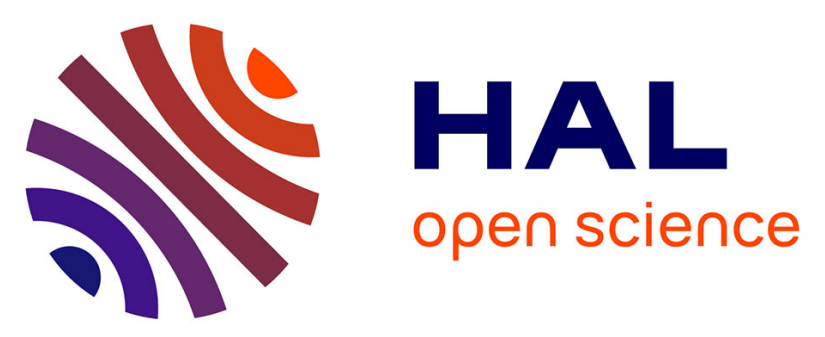

\title{
First divalent copper complex of a terdentate thiosemicarbazido-pyrazoline derived from 2,4-pentanedione bis(thiosemicarbazone): Synthesis, structural characterisation and antimicrobial in vitro activity assessment
}

Ferdaousse Rhoufal, Salaheddine Guesmi, El Mostafa Ketatni, Laurent

Jouffret, El-Kebir Hlil, Nicolas Sergent, Saï Obbade, Fouad Bentiss

\section{- To cite this version:}

Ferdaousse Rhoufal, Salaheddine Guesmi, El Mostafa Ketatni, Laurent Jouffret, El-Kebir Hlil, et al.. First divalent copper complex of a terdentate thiosemicarbazido-pyrazoline derived from 2,4pentanedione bis(thiosemicarbazone): Synthesis, structural characterisation and antimicrobial in vitro activity assessment. Polyhedron, 2021, 195, pp.114992. 10.1016/j.poly.2020.114992 . hal-03087598

\author{
HAL Id: hal-03087598 \\ https://hal.science/hal-03087598
}

Submitted on 11 Oct 2021

HAL is a multi-disciplinary open access archive for the deposit and dissemination of scientific research documents, whether they are published or not. The documents may come from teaching and research institutions in France or abroad, or from public or private research centers.
L'archive ouverte pluridisciplinaire HAL, est destinée au dépôt et à la diffusion de documents scientifiques de niveau recherche, publiés ou non, émanant des établissements d'enseignement et de recherche français ou étrangers, des laboratoires publics ou privés. 


\section{First divalent copper complex of a terdentate thiosemicarbazido-pyrazoline derived from 2,4-pentanedione bis(thiosemicarbazone): Synthesis, structural characterisation and antimicrobial in vitro activity assessment}

Ferdaousse Rhoufal ${ }^{\text {a,b }}$, Salaheddine Guesmi ${ }^{\text {a }}$, El Mostafa Ketatni ${ }^{\text {c }}$, Laurent Jouffret ${ }^{\text {d, }}$ El Kebir Hlil ${ }^{\mathrm{e}}$, Nicolas Sergent ${ }^{\mathrm{f}}$, Saïd Obbade ${ }^{\mathrm{f}}$, Fouad Bentiss ${ }^{\text {b,* }}$

${ }^{a}$ Laboratory of Coordination and Analytical Chemistry (LCCA), Faculty of Sciences, Chouaib Doukkali University, PO Box 20, M-24000 El Jadida, Morocco

${ }^{b}$ Laboratory of Catalysis and Corrosion of Materials (LCCM), Faculty of Sciences, Chouaib Doukkali University, PO Box 20, M-24000 El Jadida, Morocco

${ }^{c}$ Laboratory of Organic and Analytical Chemistry, Faculty of Science and Technology, University Sultan Moulay Slimane, PO Box 523, Beni-Mellal, Morocco

${ }^{d}$ Institut de Chimie de Clermont-Ferrand, CNRS, Université Clermont Auvergne, SIGMA Clermont, F-63000 Clermont-Ferrand, France

${ }^{e}$ Institut Néel, CNRS et Université Grenoble Alpes, BP 166, 38042 Grenoble, France

${ }^{f}$ Univ. Grenoble Alpes, Univ. Savoie Mont Blanc, CNRS, Grenoble INP, LEPMI, 38000 Grenoble, France

* Corresponding author. fbentiss@gmail.com 


\section{ABSTRACT}

Reaction of 2,4-pentanedione with thiosemicarbazide in 1:2 ratio produces cyclic pyrazoline thiosemicarbazone $\left(\mathrm{H}_{2} \mathrm{~L}^{2}\right.$ with $\left.\mathrm{L}^{2}=\mathrm{C}_{7} \mathrm{H}_{12} \mathrm{~N}_{6} \mathrm{~S}_{2}\right)$. The obtained ligand has been characterized by elemental analysis, UV-Visible, FTIR, ${ }^{1} \mathrm{H}$ and ${ }^{13} \mathrm{C}$ NMR. The results suggest that the ligand is in pyrazolinic form, and finally the structure has been confirmed by single crystal X-ray diffraction. The $\left[\left(\mathrm{L}^{2 \cdot}\right) \mathrm{Cu}(\mathrm{SCN})\right]$ copper complex has been prepared by reaction of $\mathrm{H}_{2} \mathrm{~L}^{2}$ and thiocyanate salt with copper acetates and has been fully characterized by single crystal X-ray diffraction, Hirshfeld surface analysis, as well as UV-Visible, FTIR, and Raman spectroscopies. TGA analysis and magnetic measurements were also performed. Single-crystal X-ray diffraction reveals that the complex is a neutral monomer with copper in distorted tetrahedral environment. The anionic ligand $\left(\mathrm{L}^{2 \cdot}\right)^{-}$remained in cyclic form and is coordinated as terdentate ligand (SNS). The title complex results from a double deprotonation coupled with a monoelectronic oxidation of $\mathrm{H}_{2} \mathrm{~L}^{2}$ and it may be seen as a $\mathrm{Cu}^{\mathrm{II}}$-ligand radical type complex. The copper ion is tetra coordinated $\left(\mathrm{CuN}_{2} \mathrm{~S}_{2}\right)$ by two sulfur and one nitrogen of $\left(\mathrm{L}^{2 \bullet}\right)^{-}$and by thiocyanate nitrogen atoms. The new $\left[\left(\mathrm{L}^{2 \bullet}\right) \mathrm{Cu}(\mathrm{SCN})\right]$ complex crystallizes in the monoclinic system and $C 2 / c$ space group. Full-Potential Linearized Augmented Planewave Method (FLAPW) calculations based on the Density-Functional Theory (DFT) principle are performed to shed light on both electronic and magnetic structures as well. $\left[\left(\mathrm{L}^{2 \cdot}\right) \mathrm{Cu}(\mathrm{SCN})\right]$ showed a greater activity than its parental ligand $\mathrm{H}_{2} \mathrm{~L}^{2}$ against two strains of the phytopathogenic fungus Verticillium dahliae while a moderate antibacterial activity was recorded with both against Agrobacterium tumefaciens strains and Pseudomonas syringae pv. syringae.

Keywords: Thiosemicarbazido-pyrazoline; $\mathrm{Cu}^{\mathrm{II}}$-ligand radical complex; Crystal structure; Hirshfeld surface analysis; Magnetic properties; Antimicrobial activity. 


\section{Introduction}

The chemistry of copper complexes bis(thiosemicarbazone) based ligands has been extensively studied in recent years. The interest of these compounds has increased when their properties have been demonstrated in the medical field. Indeed, several studies have shown that they are potentially interesting as chemotherapeutic [1-4], antibacterial [5] or even as radiopharmaceutical agents for hypoxia imaging [6-8] and for evaluation of Cerebral and Myocardial Blood Flow with positron emission tomography (PET) $[9,10]$. The bis(thiosemicarbazone) derivative of 2,4-pentanedione acting as tetradentate $\left(\mathrm{H}_{2} \mathrm{~L}^{1}, \mathrm{~N}_{2} \mathrm{~S}_{2}\right)($ Scheme 1a) leads, with the divalent transition metals, after a double deprotonation of the ligand, to mononuclear complexes $\left[\mathrm{M}^{\mathrm{II}} \mathrm{L}^{1}\right]$ of square planar geometry (Scheme 2) [11]. The latter exposed to the air undergo oxidation of the central carbon of the methylene group and lead to $\left[\mathrm{M}^{\mathrm{II}} \mathrm{L}^{1} \mathrm{O}\right]$ type complexes [11-13]. Bilyj et al. explained that this reaction should probably proceed via an intermediary $\mathrm{M}^{\mathrm{II}}$-ligand radical complex [13]. The same authors have described a comparative study between copper and nickel complexes bis(thiosemicarbazone) based ligands [13]. Indeed, the authors have shown that with $\mathrm{Cu}$, only the symmetrical $\left[\mathrm{M}^{\mathrm{II}} \mathrm{L}^{1}\right]$ type complex is formed which is sensitive to oxygen and turns into a $\left[\mathrm{M}^{\mathrm{II}} \mathrm{L}^{1} \mathrm{O}\right]$ type complex (Scheme 2). Whereas with $\mathrm{Ni}^{\mathrm{II}}$, they have in addition an asymmetric stable complex even in air $[13,14]$.

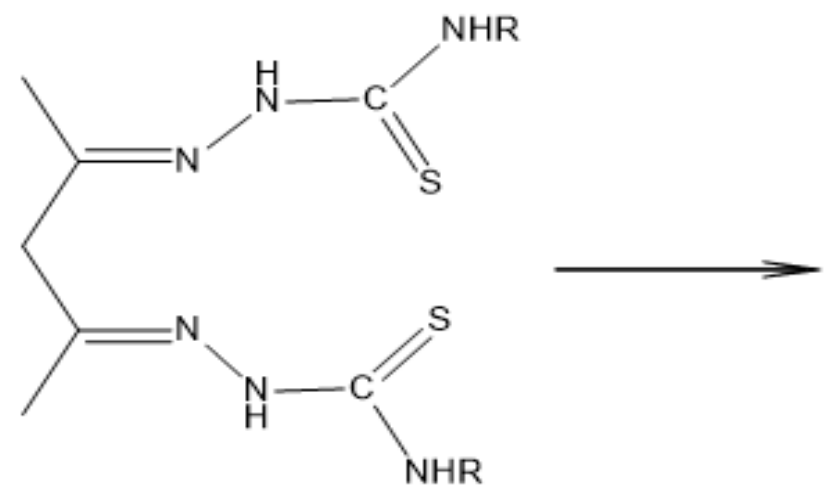

a) $\mathbf{H}_{2} \mathbf{L}^{1}$

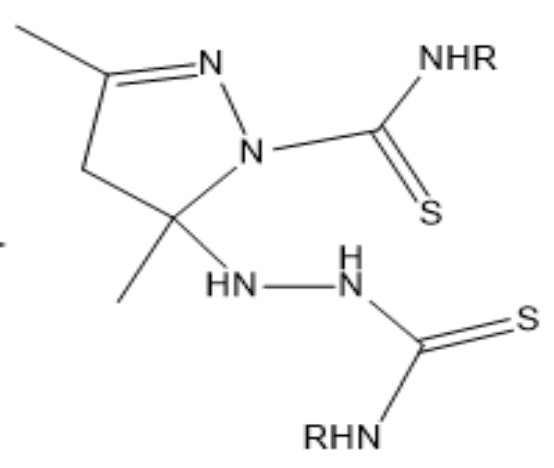

b) $\mathbf{H}_{2} \mathbf{L}^{2}$

Scheme 1. Two isomer forms a) bis(thiosemicarbazone) $\left(\mathrm{H}_{2} \mathrm{~L}^{1}\right)$ and b) thiosemicarbazido-pyrazoline $\left(\mathrm{H}_{2} \mathrm{~L}^{2}\right)$, where $\mathrm{R}=\mathrm{H}$ in this work. 
Spectro-electrochemical oxidation of crystalline $\left[\mathrm{M}^{\mathrm{II}} \mathrm{LO}\right]$ leads to a product of oxidation with two possibilities, $\mathrm{Cu}^{\mathrm{III}}$ complex or $\mathrm{Cu}^{\mathrm{II}}$ ligand centred radical [14]. Other studies have shown that this type of ligands may be seen as redox non-innocent ligands [14-16]. Others complexes with 2,4-pentadione bis(thiosemicarbazone) ligand in its mono anionic form were also obtained [3].

The oxidation at the metal level and the stabilization of unusual high oxidation states such as $\mathrm{Fe}^{\mathrm{IV}}$ and $\mathrm{Cu}^{\mathrm{III}}$, is generally done with pentane-2,4-dione bis(S-alkyl-isothiosemicarbazone $)\left(\mathrm{N}_{2} \mathrm{~N}_{2}\right)$ ligands [17-19]. However, an example of $\mathrm{N}_{2} \mathrm{~S}_{2}$ chelation system with bis(S-benzyldithiocarbazate) derivative, stabilizing $\mathrm{Cu}^{\mathrm{III}}$, was cited by Akbar Ali et al. [20]. The pro-ligand used to access these complexes $\left(\left[\mathrm{M}^{\mathrm{II}} \mathrm{L}^{1}\right]\right.$ and $\left.\left[\mathrm{M}^{\mathrm{II}} \mathrm{L}^{1} \mathrm{O}\right]\right)$, whose the structure has been controversial for a certain time [21-23]; is in fact the derivative of thiosemicarbazido-pyrazoline $\left(\mathrm{H}_{2} \mathrm{~L}^{2}\right.$, Scheme $\left.1 \mathrm{~b}\right)$ which in contact with the metal opens to coordinate in the tetradentate acyclic form, bis(thiosemicarbazone) (Scheme 2) [11-13].

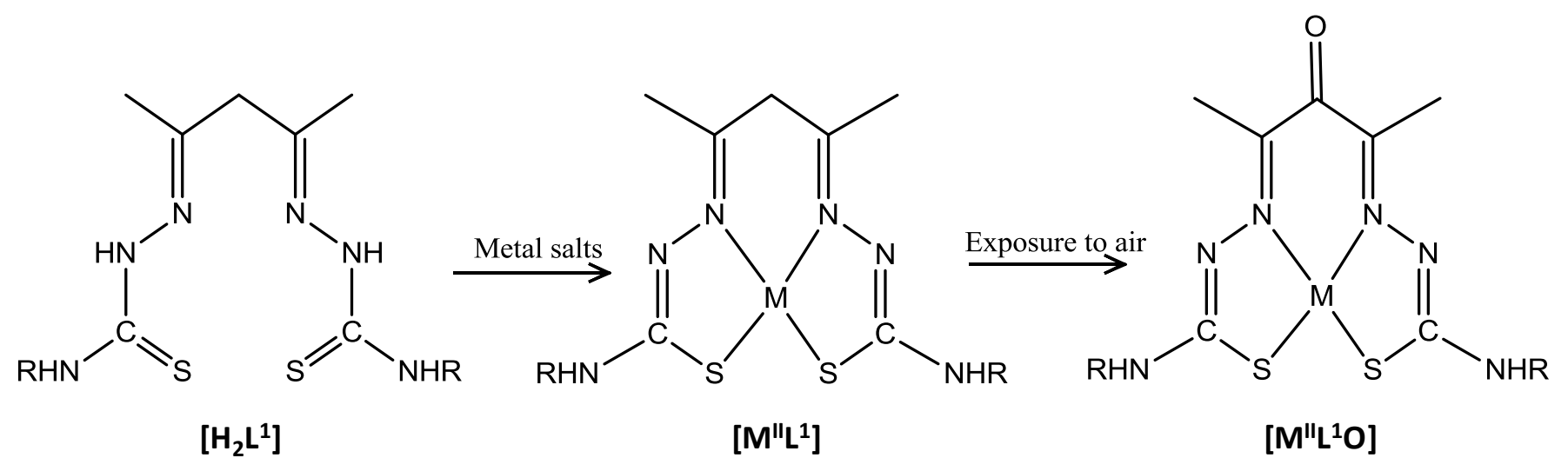

Scheme 2. Oxidative formation of $\left[\mathrm{M}^{\mathrm{II}} \mathrm{L}^{1} \mathrm{O}\right]$ type complexes.

The coordination complexes of the ligand in its pyrazolinic form were reported $[19,24]$ with their equivalents dithiocarbazatopyrazoline, but their number remains very limited. Indeed, only two examples have been described: the first one is a terdentate dithiocarbazatopyrazoline technetium (V) complex [24] and the second one is with manganese as a divalent metal with neutral dithiocarbazatopyrazoline ligand, which can be seen as the result of an oxidation after deprotonation of the initial ligand [19]. This property is well known with this kind of ligands and can be explained 
by the reaction given in the Scheme 3 [19]. However, no complex with the ligand in the pyrazolinic form has been isolated from bis(thiosemicarbazone) ligand $\left(\mathrm{H}_{2} \mathrm{~L}_{1}\right)$ to our knowledge.
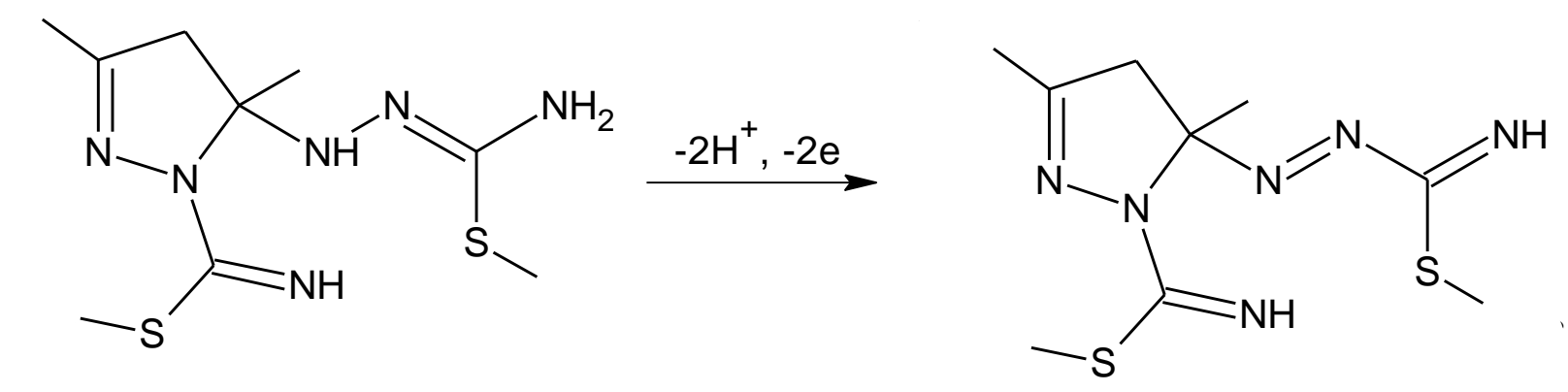

Scheme 3. "Redox non-innocent" behaviour of isothiosemicarbazido-pyrazoline leading to a neutral ligand.

In order to isolate new $\mathrm{Cu}^{\mathrm{III}}$ complexes based on bis(thiosemicarbazone) with interesting properties, we thought to use the thiocyanate ion (coordinating and anionic ligand) as a coligand which might have more beneficial biological properties. If this pseudohalide leads to complexes with activities in the electrochemical [25-27] or magnetic field [28-30], the presence of thiocyanate ions has been detected in human biological fluids, saliva and cerebrospinal and in oral cavities in case of stress [31-36]. Its role has also been demonstrated in the biological field as a detoxifier [37]. In this work, we confirm the pyrazolinic form of the ligand via a crystallographic study. Moreover, we investigate the reaction of the divalent copper acetates with the pyrazoline ligand $\left(\mathrm{H}_{2} \mathrm{~L}^{2}\right)$ in the presence of $\mathrm{SCN}^{-}$, which unexpectedly gives the first copper complex $\left[\left(\mathrm{L}^{2 \cdot}\right) \mathrm{Cu}(\mathrm{SCN})\right]$ with terdentate carbamothioyldiazenyl-pyrazoline (SNS) and thiocyanate ion as coligand, whose metal is in tetrahedral geometry. This complex can be described as the result of a double deprotonation coupled with a monoelectronic oxidation and it may be regarded as a $\mathrm{Cu}^{\text {II }}$-ligand radical type complex. Hirshfeld surface analysis, spectroscopic characterisations (IR, UV-Visible, NMR and Raman) and thermal studies of $\left(\mathrm{H}_{2} \mathrm{~L}^{2}\right)$ and $\left[\left(\mathrm{L}^{2 \cdot}\right) \mathrm{Cu}(\mathrm{SCN})\right]$ were performed. The magnetic properties of the title copper complex were also studied. Indeed, an attention is paid to DFT calculations to investigate both electronic and magnetic structures using FLAPW method. In addition, we have evaluated the activity of the ligand $\mathrm{H}_{2} \mathrm{~L}^{2}$ and its complex $\left[\left(\mathrm{L}^{2 \bullet}\right) \mathrm{Cu}(\mathrm{SCN})\right]$ against several fungal and bacterial diseases affecting crops, including Verticillium dahliae, Fusarium 
oxysporum $f s p$. melonis, Pseudomonas syringae pv. syringae, P. syringae pv. tabaci and Agrobacterium tumefaciens. To the best of our knowledge, the activity of thiosemicarbazidepyrazoline derivatives against phytopathogens has never been reported.

\section{Experimental}

\subsection{Materials}

All solvents and reagents for synthesis were purchased from Aldrich and Merck and used as received without further recrystallization or distillation.

\subsubsection{Synthesis of thiosemicarbazido-pyrazoline $\left(\mathrm{H}_{2} \mathrm{~L}^{2}\right)$}

The thiosemicarbazido-pyrazoline ligand $\left(\mathrm{H}_{2} \mathrm{~L}^{2}\right)$ has been synthesized using the method previously reported [21]. Anal. Calc. for $\mathrm{C}_{7} \mathrm{H}_{14} \mathrm{~N}_{6} \mathrm{~S}_{2}$. C, 34.13; H, 5.73; N, 34.11; S, 26.03; Found: C, 34.19; H, 5.68; N, 34.15; S, 26.08. Selected spectroscopic data: ${ }^{1} \mathrm{H}$ NMR (300 MHz, DMSO-d 6 ): (ppm) $1.71\left(3 \mathrm{H}, 5-\mathrm{CH}_{3}, \mathrm{~s}\right), 1.94\left(3 \mathrm{H}, 3-\mathrm{CH}_{3}, \mathrm{~s}\right), 2.81\left(2 \mathrm{H}\right.$, ring $\left.\mathrm{CH}_{2}, J_{\mathrm{AB}}=18.75 \mathrm{~Hz}, \mathrm{q}\right), 6.49(1 \mathrm{H}, 5-$ $\mathrm{NH}, \mathrm{s}), 7.43\left(1 \mathrm{H}, \mathrm{NH}_{2}, \mathrm{~s}\right), 7.61\left(1 \mathrm{H}, \mathrm{NH}_{2}, \mathrm{~s}\right), 7.79\left(2 \mathrm{H}, \mathrm{NH}_{2}, \mathrm{~s}\right), 8.09(1 \mathrm{H}, 5-\mathrm{N}-\mathrm{NH}, \mathrm{s}) .{ }^{13} \mathrm{C}$ NMR $(75$ MHz, dimethyl-d $\mathrm{d}_{6}$ sulfoxide): (ppm) $16.33\left(3-\mathrm{CH}_{3}\right), 23.92\left(5-\mathrm{CH}_{3}\right), 47.29$ (4-C), 84.89 (5-C), $155.56(\mathrm{C}=\mathrm{N}), 175.13(\mathrm{C}=\mathrm{S}), 183.10(\mathrm{C}=\mathrm{S})$, FTIR $\left(\mathrm{ATR}, \mathrm{cm}^{-1}\right): 3423(\mathrm{~m})[v(\mathrm{NH})], 3302(\mathrm{w})$, 3232(m) $\left[v\left(\mathrm{NH}_{2}\right)\right], 3193(\mathrm{~m}), 3143(\mathrm{~m})\left[v\left(\mathrm{NH}_{2}\right)\right], 1579(\mathrm{~s})[v(\mathrm{C}=\mathrm{N})] . \mathrm{UV}-\mathrm{Vis}\left(\lambda_{\max }, \mathrm{nm}\left(\varepsilon_{\max }, \mathrm{M}^{-1} \mathrm{~cm}^{-}\right.\right.$ $\left.\left.{ }^{1}\right)\right)$ in DMF: 266 (24322), 276 (22052).

\subsubsection{Synthesis of $\left[\left(L^{2 \cdot}\right) C u(S C N)\right]$}

To a solution of $\mathrm{H}_{2} \mathrm{~L}^{2}(0.1 \mathrm{mmol}, 24.6 \mathrm{mg})$ dissolved in acetone $(25 \mathrm{~mL})$, under magnetic stirring at room temperature, was added successively an aqueous solution $(5 \mathrm{~mL})$ of $\mathrm{Cu}\left(\mathrm{CH}_{3} \mathrm{COO}\right)_{2}$, $\mathrm{H}_{2} \mathrm{O}(0.1 \mathrm{mmol}, 17 \mathrm{mg})$ and $\mathrm{KSCN}(0.1 \mathrm{mmol}, 10 \mathrm{mg})$. The reaction mixture obtained is stirred for $15 \mathrm{~min}$ and after seven days of slow evaporation of the solvent, black crystals were isolated, washed with ether and air-dried at room temperature (75\%) Anal. Calc. for $\left(\mathrm{C}_{8} \mathrm{H}_{12} \mathrm{~N}_{7} \mathrm{~S}_{3} \mathrm{Cu}\right): \mathrm{C}, 26.26 ; \mathrm{H}$, 
3.31; N, 26.79; S, 26.29; Found: C, 26.89; H, 3.38; N, 26.51; S, 26.27. Selected spectroscopic data: FTIR (ATR, $\left.\mathrm{cm}^{-1}\right): 3376(\mathrm{~m}), 3243(\mathrm{~m})\left[v\left(\mathrm{NH}_{2}\right)\right] ; 3152(\mathrm{~m}), 3138(\mathrm{~m})\left[v\left(\mathrm{NH}_{2}\right)\right] ; 2115(\mathrm{~s})\left[v\left(\mathrm{NCS}^{-}\right)\right]$; 1598(s) $[v(\mathrm{C}=\mathrm{N})] . \mathrm{UV}-\mathrm{Vis}\left(\lambda_{\max }, \mathrm{nm}\left(\varepsilon_{\max }, \mathrm{M}^{-1} \mathrm{~cm}^{-1}\right)\right)$ in DMF: 268 (25039), 280 (114856), 376 (2831), 465 (2366), and 717 (1822).

\subsection{Crystal X-ray data collection}

Single crystals were selected for the X-ray diffraction (XRD) data collection and mounted with cryoloops on a Bruker APEX II diffractometer with a MoK $\mathrm{M}_{\alpha}$ graphite-monochromated radiation $(\lambda=0.71073 \AA)$. The diffractometer is equipped with a CCD bidimensional detector and an OXFORD CRYOSTREAM 700 system to cool the sample to $173 \mathrm{~K}$ [38]. The ligand thiosemicarbazido-pyrazoline $\left(\mathrm{H}_{2} \mathrm{~L}^{2}\right)$ crystals all presented twinning along the $\left(\begin{array}{lll}0 & 0 & 1\end{array}\right)$ axis, thus requiring longer data acquisition than the copper containing crystals. SAINT+ 6.02 program was used for extraction and integration of diffraction intensities [39] and SADABS program was carried out for correction of absorption effect [40]. The structures were solved by direct methods using SHELXL [41] and refined (by weighted full matrix least-square on $F^{2}$ techniques) to convergence using the SHELXL program. All non-hydrogen atoms were refined anisotropically. All hydrogen atoms were positioned geometrically and refined using a riding model.

\subsection{Hirshfeld surface analysis}

The Hirshfeld surfaces calculated for $\mathrm{H}_{2} \mathrm{~L}^{2}$ ligand and $\left[\left(\mathrm{L}^{2 \cdot}\right) \mathrm{Cu}(\mathrm{SCN})\right]$ complex structures were analysed to clarify the nature of the intermolecular interactions between different units in the crystal packing motifs. Thus, a Hirshfeld surface analysis [42] and the associated two-dimensional fingerprint plots [43] were performed using CrystalExplorer17.5 [44] to figure out the normalized contact distance $\left(d_{\text {norm }}\right)$, which depends on contact distances to the closest atoms outside $\left(d_{\mathrm{e}}\right)$ and inside $\left(d_{\mathrm{i}}\right)$ the surface. The 3D $d_{\text {norm }}$ surfaces are mapped over a fixed colour scale of -0.3499 to 1.4225 for $\mathrm{H}_{2} \mathrm{~L}^{2}$, and -0.3187 to 1.2588 a.u. for $\left[\left(\mathrm{L}^{2 \bullet}\right) \mathrm{Cu}(\mathrm{SCN})\right]$. The electrostatic potential were 
generated using TONTO implanted in Crystal Explorer 17.5 with the 6-311g(d,p) basis set at the Hartree-Fock level of theory, energy in the range -0.0789 to +0.1276 a.u for $\mathrm{H}_{2} \mathrm{~L}^{2}$ and -0.0944 to +0.1399 a.u for complex molecule.

\subsection{Physical measurements}

UV-Visible absorption spectra in dimethylformamide (DMF) solvent were recorded in the range 250-800 nm using a Perkin Elmer Lambda 365 spectrophotometer.

FTIR spectra were recorded on a SHIMADZU FT-IR 8400S spectrometer with a Smart iTR attachment and diamond attenuated total reflectance (ATR) crystal in the range 500-4000 $\mathrm{cm}^{-1}$.

The ${ }^{1} \mathrm{H}$ and ${ }^{13} \mathrm{C}$ NMR spectra of $\mathrm{H}_{2} \mathrm{~L}^{2}$ were recorded with the Bruker AVANCE 300 at $25{ }^{\circ} \mathrm{C}$. All chemical shifts ${ }^{1} \mathrm{H}$ and ${ }^{13} \mathrm{C}$ are given in ppm using dimethyl sulfoxide- $d_{6}$ (DMSO- $d_{6}$ ) as solvent.

Element analyses (C, H, N and S) were performed on a VARIO-ELEMENTAR analyser.

Raman spectra have been acquired with a Renishaw InVia spectrometer in micro-Raman configuration (objective $\times 50$ ) equipped with a Peltier cooled CCD detector. The $785 \mathrm{~nm}$ excitation line of a LASER diode have been used at a power less than $3 \mathrm{~mW}$ onto the sample in order to avoid local heating.

Thermogravimetric analysis (TGA) was carried out on a SDT-Q600 thermal analyser and platinum crucibles, in the range of room temperature to $800^{\circ} \mathrm{C}$ under air flow $(99 \mathrm{ml} / \mathrm{min})$ with $5{ }^{\circ} \mathrm{C}$ $\min ^{-1}$ fixed heating rate. The TGA curve has been normalized with respect to the sample weight.

Magnetic measurements were carried out using the commercial Physical Properties Measurements System device (Quantum Design, PPMS), and magnetization M(T) was measured versus temperature ranging from 2 to $400 \mathrm{~K}$, under an external magnetic field of $0.05 \mathrm{~T}$. The magnetic field dependence of the magnetization $\mathrm{M}(\mathrm{H})$ was also measured at $2 \mathrm{~K}$ by varying the applied magnetic field between -6 and $6 \mathrm{~T}$.

\subsection{Electronic structure calculations}


We used FLAPW method which performs DFT calculations using the local density approximation [45]. The Kohn-Sham equation and energy functional were evaluated consistently using the Full Potential Linearized Augmented Plane Wave (FLAPW) method. For this method, the space was divided into the interstitial and the non-overlapping muffin tin spheres centred on the atomic site. The employed basis function inside each atomic sphere was a linear expansion of the radial solution of a spherically potential multiplied by spherical harmonics. In the interstitial region the wave function was taken as an expansion of plane waves and no shape approximation for the potential was introduced in this region which is consistent with the full potential method. The core electrons were described by atomic wave functions which were solved relativistically using the current spherical part; the valence electrons were also treated relativistically in our case. These FLAPW calculations were performed with our crystal structure parameters. Here, polarized spin as well as the ferromagnetic state were considered for all atoms of our compound.

\subsection{In vitro antimicrobial activity}

Antifungal screening was performed against three strain of Verticillium dahliae (SE, SH and SJ), previously isolated from olive trees in different region in Morocco and one isolate of Fusarium oxysporum fsp. melonis (FOM). They were sub-cultured on potato dextrose agar (PDA) plates at $27^{\circ} \mathrm{C}$ in the dark. $\mathrm{H}_{2} \mathrm{~L}^{2}$ and $\left[\left(\mathrm{L}^{2 \cdot}\right) \mathrm{Cu}(\mathrm{SCN})\right]$ were dissolved in $0.2 \%$ DMSO and added at concentrations of 50, 100 and $200 \mu \mathrm{g} \mathrm{mL}^{-1}$ to the PDA medium before being autoclaved and cooled. The amended media was poured into Petri dishes and inoculated using $5 \mathrm{~mm}$ plugs of agar and mycelium taken from actively growing cultures of fungus on PDA. Petri plates were incubated in the dark at $27^{\circ} \mathrm{C}$. The mycelial growth was assessed by measuring 2 orthogonal diameters of each colony after 7 days of incubation. Mycelial growth was compared with growth on PDA amended with $0.2 \%$ DMSO (control) and the percentage of inhibition growth was expressed [46] relative to the control. The regression line between colony diameter of the pathogen and log concentration of 
products was determined. Sensitivity was then measured using effective IC50 values. The experiment was repeated 3 times.

The in vitro antibacterial screening of the two compounds were performed against the following phytopathogenic bacteria: Agrobacterium tumefaciens (Ach5, A281 and C58 strains), Pseudomonas syringae pv. tabaci (strain CFBP2106) and Pseudomonas syringae pv. syringae (strain CFBP692). A. tumefaciens strains were sub-cultivated on LB solid medium while $P$. syringae pv. syringae and $P$. syringae pv. tabaci were cultured on King B (KB) medium at $28^{\circ} \mathrm{C}$. Antibacterial activities of the two compounds were investigated by the agar disc diffusion method as described previously [47]. Bacteria that were grown overnight were diluted to a concentration of $3 \times 10^{8} \mathrm{CFU} . \mathrm{mL}^{-1}$. Sterile cellulose discs of $6 \mathrm{~mm}$ diameter were impregnated with the products (200 $\mu \mathrm{g} \mathrm{mL}^{-1}$ in $0.2 \%$ DMSO) and discs were placed on either LB or KB solid medium previously amended with $3 \times 10^{8} \mathrm{CFU} \mathrm{mL} \mathrm{m}^{-1}$ of bacteria. DMSO (0.2\%) was used as a negative control. The inoculated plates were incubated at $28^{\circ} \mathrm{C}$ for $48 \mathrm{~h}$. The antimicrobial activity was evaluated by measuring the clearance zone around the discs which indicates a positive antibacterial activity of the respective products. Each experiment was repeated 3 times.

All data were expressed as the mean and confidence intervals. Data were subjected to ANOVA, and means were compared using Tukey's test and $p$ values of 0.05 were considered to be significantly different.

\section{Results and discussion}

\subsection{Crystal structure determination and description}

The title complex $\left[\left(\mathrm{L}^{2 \bullet}\right) \mathrm{Cu}(\mathrm{SCN})\right]$ was obtained by reaction, at room temperature, of copper acetate with $\mathrm{H}_{2} \mathrm{~L}^{2}$ in the presence of the pseudohalide $\mathrm{SCN}^{-}$as illustrated in Scheme 4. The organic ligand obtained from acetylacetone and thiosemicarbazide [21] did not lead to 2,4-pentanedione bis(thiosemicarbazone) but to its cyclic correspondent $\mathrm{H}_{2} \mathrm{~L}^{2}$ (Scheme 1). The pyrazoline form of the ligand has been suggested by its spectroscopic properties and confirmed by single crystal X-ray 
diffraction. Arion having proposed the structure of $\mathrm{H}_{2} \mathrm{~L}^{2}$ [16] without further structural details, therefore we decided to determine the crystallographic structure of this ligand in order to be able to make comparison with its copper complex. The structural study of the new title copper complex reveals that it is an unexpectedly copper complex pyrazoline terdentate ligand doubly deprotonated with thiocyanate ion $\left(\mathrm{SCN}^{-}\right)$coordinated via nitrogen atom. The oxidation state of the metal is formally $\mathrm{Cu}^{\mathrm{III}}$ where the pyrazolinic ligand should be in dianionic form $\left(\mathrm{L}^{2}\right)^{2-}$, but the ligand being potentially redox-active (non-innocent), the possibility of a $\mathrm{Cu}^{\mathrm{II}}$ ligand-radical with the organic ligand in monoanionic form $\left(\mathrm{L}^{2 \cdot}\right)^{-}$cannot be excluded as shown in scheme 4. The mechanism that we propose starts with a mono deprotonated intermediate (complex A in Scheme 4), which has been suggested by Bylij et al. but with an acetate in place of the thiocyanate and leads to classical complexes with the open form of the ligand [14].
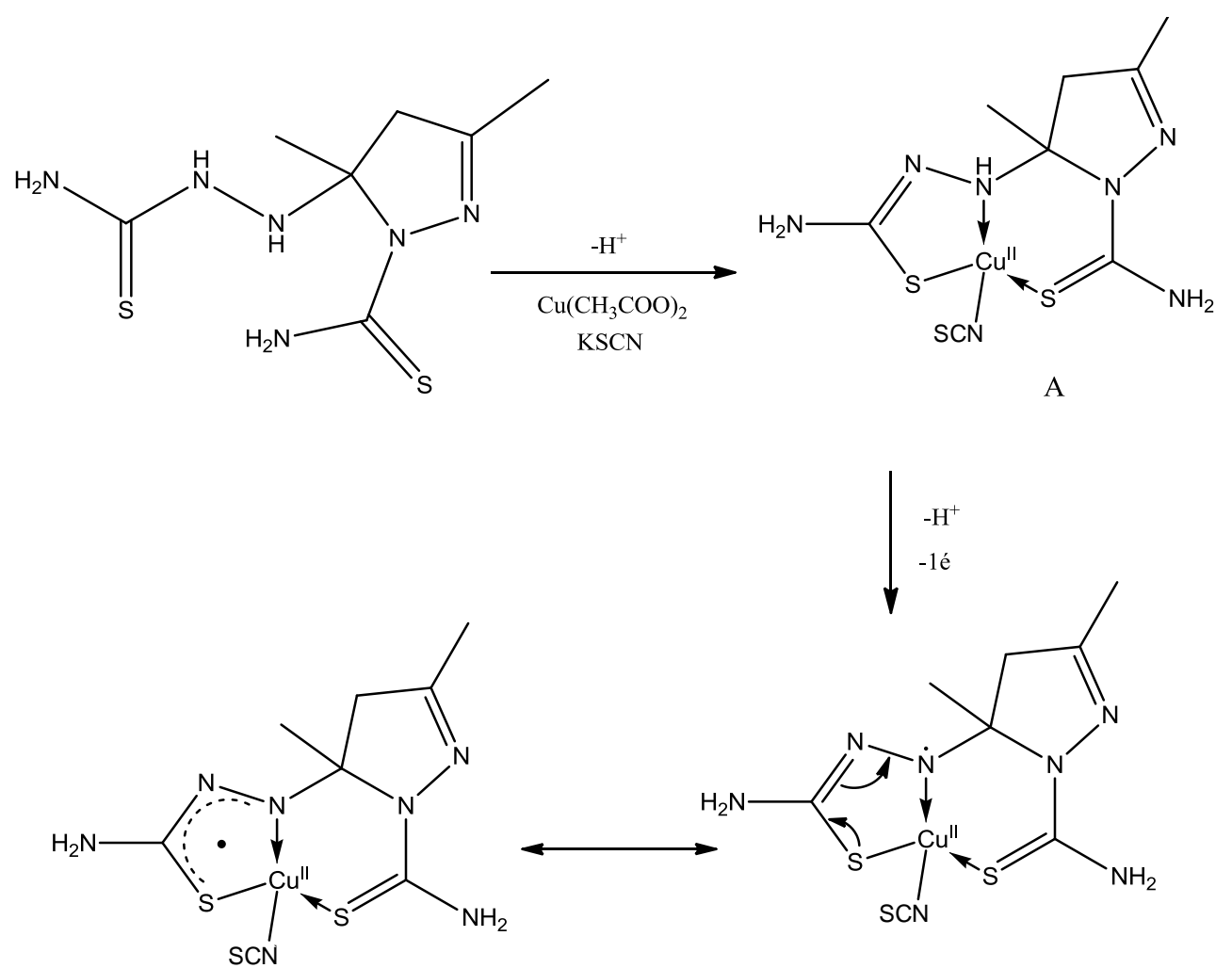

Scheme 4. Proposed mechanism of the formation reaction of copper complex $\left[\left(\mathrm{L}^{2 \cdot}\right) \mathrm{Cu}(\mathrm{SCN})\right]$.

For both compounds, the crystal structures were determined in monoclinic symmetry, where the $\mathrm{H}_{2} \mathrm{~L}^{2}$ ligand and its copper complex $\left[\left(\mathrm{L}^{2 \cdot}\right) \mathrm{Cu}(\mathrm{SCN})\right]$ crystallize in the centrosymmetric space 
groups $P 22_{1} / c$ and $C 2 / c$, with four and eight formula per unit cell, respectively. The crystal structures determination details of both compounds are given in Table 1, with atomic positions, isotropic thermal displacement factors, selected bond lengths and angles given in Tables S1-S6 of supplementary information file. Visualization of both structures were made with the Diamond 3.1 program [48].

\section{Table 1}

Single crystal and structure refinement data for $\mathrm{H}_{2} \mathrm{~L}^{2}$ ligand and $\left[\left(\mathrm{L}^{2 \cdot}\right) \mathrm{Cu}(\mathrm{SCN})\right]$ complex.

\begin{tabular}{|c|c|c|}
\hline Chemical formula & $\mathrm{H}_{2} \mathrm{~L}^{2}: \mathrm{C}_{7} \mathrm{H}_{14} \mathrm{~N}_{6} \mathrm{~S}_{2}$ & {$\left[\left(\mathrm{~L}^{2 *}\right) \mathrm{Cu}(\mathrm{SCN})\right]: \mathrm{C}_{8} \mathrm{H}_{12} \mathrm{CuN}_{7} \mathrm{~S}_{3}$} \\
\hline Formula weight $(\mathrm{g} / \mathrm{mol})$ & 246.36 & 365.97 \\
\hline Temperature (K) & $173(2)$ & $173(2)$ \\
\hline Wavelength $(\AA)$ & 0.71073 & 0.71073 \\
\hline Crystal size (mm) & $0.134 \times 0.168 \times 0.250$ & $0.140 \times 0.168 \times 0.257$ \\
\hline Crystal system & monoclinic & monoclinic \\
\hline Space group & $P 2{ }_{1} / c$ & $C 2 / c$ \\
\hline \multirow[t]{3}{*}{ Unit cell dimensions $(\AA)$} & $a=8.7329(10)$ & $a=15.684(3)$ \\
\hline & $b=8.9424(9), \beta=105.802(4)^{\circ}$ & $b=10.9895(18), \beta=90.236(5)^{\circ}$ \\
\hline & $c=15.7709(18)$ & $c=16.758(3)$ \\
\hline Volume $\left(\AA^{3}\right)$ & $1185.1(2)$ & 2888.4(9) \\
\hline $\mathrm{Z}$ & 4 & 8 \\
\hline Density (calculated) $\left(\mathrm{g} / \mathrm{cm}^{3}\right)$ & 1.381 & 1.683 \\
\hline Absorption coefficient $\left(\mathrm{mm}^{-1}\right)$ & 0.429 & 1.942 \\
\hline$F(000)$ & 520 & 1488 \\
\hline \multicolumn{3}{|c|}{ Data collection and structure refinement } \\
\hline Theta range for data collection $\left({ }^{\circ}\right)$ & 2.42 to 30.51 & 3.32 to 31.51 \\
\hline Index ranges & $-12<=h<=12,-12<=k<=12,-22<=l<=22$ & $\begin{array}{l}-23<=h<=23,-16<=k<=16,- \\
24<=l<=24\end{array}$ \\
\hline Reflections collected & 46262 & 56787 \\
\hline Independent reflections & $3608\left[R_{(\mathrm{int})}=0.0507\right]$ & $4809\left[R_{(\mathrm{int})}=0.0611\right]$ \\
\hline$T_{\max } / T_{\min }$ & $0.945 / 0.900$ & $0.7730 / 0.6350$ \\
\hline Resolution technique & Direct methods & Direct methods \\
\hline Refinement method & Full-matrix least-squares on $F^{2}$ & Full-matrix least-squares on $F^{2}$ \\
\hline Refinement program & SHELXL-2018/3 & SHELXL-2018/3 \\
\hline Function minimized & $\Sigma \mathrm{w}\left(F_{\mathrm{o}}^{2}-F_{\mathrm{c}}^{2}\right)^{2}$ & $\Sigma \mathrm{w}\left(F_{\mathrm{o}}^{2}-F_{\mathrm{c}}^{2}\right)^{2}$ \\
\hline Data/restraints/parameters & $3608 / 0 / 144$ & $4809 / 0 / 174$ \\
\hline Goodness-of-fit on $\mathrm{F}^{2}$ & 1.231 & 1.028 \\
\hline Final $R$ indices & $\begin{array}{l}3191 \text { data; } I>2 \sigma(I) \quad R_{1}=0.0792 \\
\mathrm{w} R_{2}=0.2049\end{array}$ & $\begin{array}{l}3159 \text { data; } I>2 \sigma(I) R_{1}=0.0331, \\
\mathrm{w} R_{2}=0.0753\end{array}$ \\
\hline Weighting scheme & $\begin{array}{l}\text { All data, } R_{1}=0.0865, \mathrm{w} R_{2}=0.2081 \\
W=1 /\left[\sigma^{2}\left(F_{\mathrm{o}}^{2}\right)+10.2460 P\right] \text { where } \\
P=\left(F_{\mathrm{o}}^{2}+2 F_{\mathrm{c}}^{2}\right) / 3\end{array}$ & $\begin{array}{l}\text { All data, } R_{1}=0.0645, \mathrm{w} R_{2}=0.0873 \\
W=1 /\left[\sigma^{2}\left(F_{\mathrm{o}}^{2}\right)+(0.0352 P)^{2}+\right. \\
1.3732 P] \text { where } P=\left(F_{\mathrm{o}}^{2}+2 F_{\mathrm{c}}^{2}\right) / 3\end{array}$ \\
\hline Largest diff. peak and hole $\left(\mathrm{e}^{-3}\right)$ & 0.568 and -0.546 & 0.350 and -0.411 \\
\hline R.M.S. dev. from mean $\left(\mathrm{e} \AA^{-3}\right)$ & 0.145 & 0.062 \\
\hline
\end{tabular}


The crystal structure views of the asymmetric units of ligand and its complex are shown in Fig. 1a and $1 b$, respectively. Thus, we can observe that during the reaction of the ligand $\mathrm{H}_{2} \mathrm{~L}^{2}$ in the aqueous solution of $\mathrm{Cu}\left(\mathrm{CH}_{3} \mathrm{COO}\right)_{2}$ and $\mathrm{KSCN}$, the formation of $\left[\left(\mathrm{L}^{2 \cdot}\right) \mathrm{Cu}(\mathrm{SCN})\right]$ resulted from the two protons loss of nitrogen atoms $\mathrm{N} 2$ and $\mathrm{N} 3$ of the ligand $\mathrm{H}_{2} \mathrm{~L}^{2}$, following the complexation mechanism given in Scheme 4.

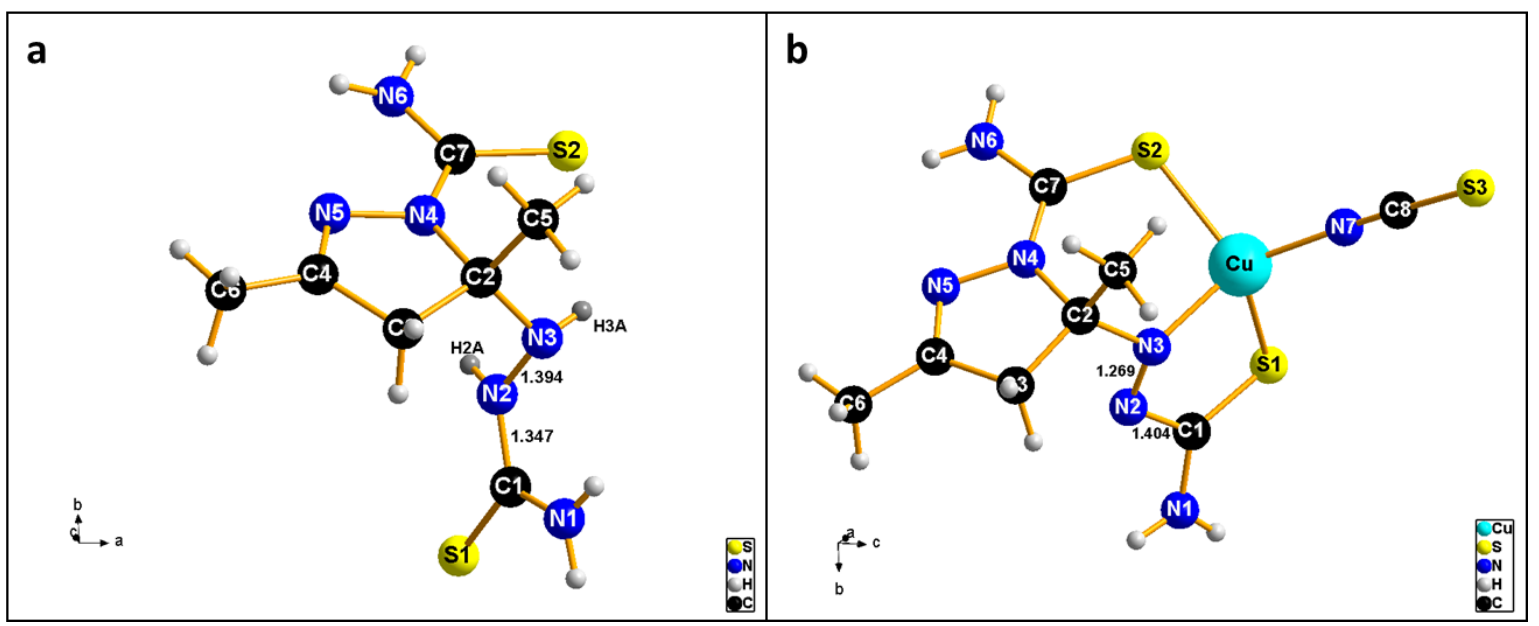

Fig. 1. Molecular structure of (a) ligand $\mathrm{H}_{2} \mathrm{~L}^{2}$ and (b) copper complex $\left[\left(\mathrm{L}^{2 \cdot}\right) \mathrm{Cu}(\mathrm{SCN})\right]$.

In the crystal structure view of the $\left[\left(\mathrm{L}^{2 \cdot}\right) \mathrm{Cu}(\mathrm{SCN})\right]$ molecule shown in Fig. $1 \mathrm{~b}$, the asymmetric unit is formed of $\mathrm{Cu}$ atom occupying a general position, linked by $\mathrm{S} 1, \mathrm{~S} 2$ and N3 atoms to $\left(\mathrm{L}^{2 \cdot}\right)^{-}$unit and by $\mathrm{N} 7$ atom to thiocyanate ion $\left(\mathrm{SCN}^{-}\right)$, to form a deformed tetrahedral environment $\mathrm{CuS}_{2} \mathrm{~N}_{2}$, in which both $\mathrm{Cu}-\mathrm{N}$ bond distances $[\mathrm{Cu}-\mathrm{N} 7=1.912(2) \AA, \mathrm{Cu}-\mathrm{N} 3=1.954(1) \AA]$ are shorter than $\mathrm{Cu}-\mathrm{S}$ bond length bond $[\mathrm{Cu}-\mathrm{S} 2=2.282(1) \AA, \mathrm{Cu}-\mathrm{S} 1=2.339(1) \AA]$, typical of $\mathrm{Cu}-\mathrm{N}$ and $\mathrm{Cu}-\mathrm{S}$ bond length in $\mathrm{Cu}(\mathrm{II})$-complexes, knowing that for $\mathrm{Cu}(\mathrm{III})$ complexes the average of $\mathrm{Cu}-$ S bond length is of 2.17 to $2.20 \AA$, respectively [19,20,49-51]. The values of the two trans angles $\mathrm{N} 7-\mathrm{Cu}(1)-\mathrm{N} 3=133.9(1)^{\circ}, \mathrm{S} 1-\mathrm{Cu}-\mathrm{S} 2=124.1(1)^{\circ}$ and of the four $\mathrm{N}-\mathrm{Cu}-\mathrm{S}$ bond angles of 83.3(1), 96.2(1), 109.3(1) and $110.2(1)^{\circ}$, clearly indicating a large tetrahedral distortion around $\mathrm{Cu}$ atoms. In the crystal structure of $\left[\left(\mathrm{L}^{2 \cdot}\right) \mathrm{Cu}(\mathrm{SCN})\right]$ complex, the bond angle $\mathrm{N} 2-\mathrm{N} 3-\mathrm{C} 2=112.1(1)^{\circ}$ is indicative of the deformed hybridization of the $\mathrm{N} 3$ atom, and the $\mathrm{Cu}-\mathrm{N} 3$ bond length of 1.954(1) $\AA$ is typical of the copper nitrogen bond. The bond distances C1-N2 and N4-N5 of 1.404(3) and $1.403(2) \AA$, respectively, are typical values of single bonds, while the short distance $1.269(2) \AA$ of 
$\mathrm{N} 2-\mathrm{N} 3$ indicate a double $\mathrm{N}=\mathrm{N}$ bond. The pyrazole bond lengths, N5-N4 =1.403(2) $\AA, \mathrm{N} 4-\mathrm{C} 2=$ 1.483(2) $\AA, \mathrm{C} 2-\mathrm{C} 3=1.536(3) \AA, \mathrm{C} 3-\mathrm{C} 4=1.484(3) \AA$ and $\mathrm{C} 4-\mathrm{N} 5=1.278(2) \AA$, clearly indicate that $\mathrm{C} 4-\mathrm{N} 5$ is the only double bond in the pyrazole ring. The N5-C4-C6 $=123.3(2)^{\circ}$ and N4-C2$\mathrm{C} 5=112.73(17)^{\circ}$ bond angles values, also show the $s p^{2}$ and $s p^{3}$ hybridization of the $\mathrm{C} 4$ and $\mathrm{C} 2$ carbon atoms, respectively. In addition, there is an abnormally large difference in the bond angles $\mathrm{Cu}-\mathrm{S} 1-\mathrm{C} 1=93.51(7)^{\circ}$ and $\mathrm{Cu}-\mathrm{S} 2-\mathrm{C} 7=107.94(7)^{\circ}$, this can be explained by the geometric constraints imposed by the tetrahedral nature of the complex. The thiocyanate ion $\mathrm{SCN}^{-}$is bound through the nitrogen atom and is practically linear with $\left(\mathrm{N} 7-\mathrm{C} 8-\mathrm{S} 3=178.48(2)^{\circ}\right)$, while the $\mathrm{Cu}-$ NCS bond is curved with $\mathrm{Cu}-\mathrm{N} 7-\mathrm{C} 8$ angle of $165.48(9)^{\circ}$. One can also note that the copper complexation with $\mathrm{H}_{2} \mathrm{~L}^{2}$ ligand, via the $\mathrm{N} 3, \mathrm{~S} 1$ and $\mathrm{S} 2$ atoms, has resulted in a large contraction of the ligand single bond $(\mathrm{N} 2-\mathrm{N} 3=1.399(5) \AA)$, which is due to the protons $\mathrm{H}^{+}$loss of the nitrogen atom $\mathrm{N} 2$, to give a double bond $(\mathrm{N} 2=\mathrm{N} 3=1.269(2) \AA)$ in the complex. Whereas, the $\mathrm{C}-\mathrm{S}$ bonds length remain unchanged in the two compounds with mean value of 1.697(4) and 1.687(2) $\AA$ for the ligand and the complex, respectively.

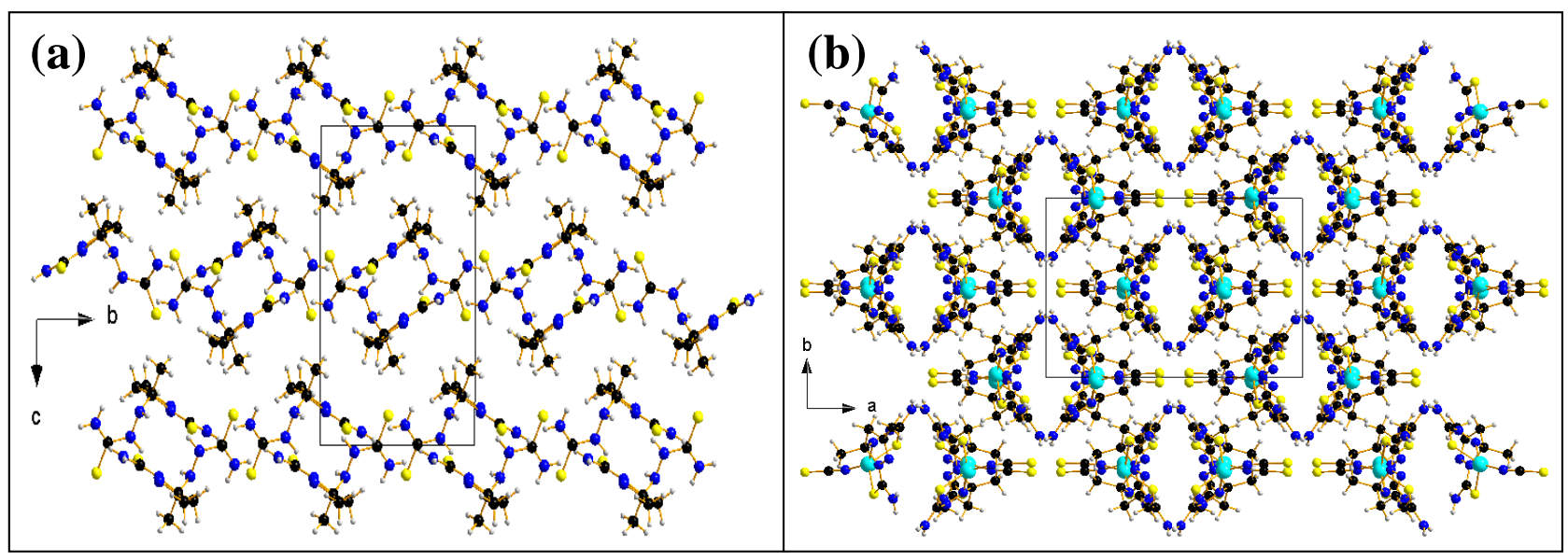

Fig. 2. Crystal structure view of (a) ligand $\mathrm{H}_{2} \mathrm{~L}^{2}$ in the $(b, c)$ plan and (b) of copper complex $\left[\left(\mathrm{L}^{2 \cdot}\right) \mathrm{Cu}(\mathrm{SCN})\right]$ along $c$ axis.

Thus, the crystal structures of ligand and its copper complex, presented in the Figs. 2a and $2 \mathrm{~b}$, show the existence of infinite chains along $b$ axis and large tunnels following $c$ direction, in the ligand and complex respectively. For both compounds the stabilization of the crystal structure is 
ensured, as is often observed in several coordination complexes, by usual weak interactions, where each $\mathrm{H}_{2} \mathrm{~L}^{2}$ ligand and $\left[\left(\mathrm{L}^{2 \bullet}\right) \mathrm{Cu}(\mathrm{SCN})\right]$ complex interacts with neighbouring molecules via conventional hydrogen bonds $\mathrm{D}-\mathrm{H} \cdots \mathrm{A}$ with $(\mathrm{D}=\mathrm{C}, \mathrm{N}$ and $\mathrm{A}=\mathrm{S}, \mathrm{C}, \mathrm{N})$, with in addition dipolar hydrogen $\mathrm{N}-\mathrm{H} \cdots \mathrm{H}-\mathrm{D}$ interactions for the ligand and sulfur $\mathrm{S} \cdots \mathrm{S}$ interactions in the complex, as notified in Tables 2 and 3.

\section{Table 2}

$\mathrm{H} \cdots \mathrm{H}$ and D-H $\cdots$ A hydrogen-bond geometry of $\mathrm{H}_{2} \mathrm{~L}^{2}(\mathrm{D}=\mathrm{C}, \mathrm{N}$ and $\mathrm{A}=\mathrm{S}, \mathrm{C}, \mathrm{N})$.

\begin{tabular}{llll}
\hline $\mathrm{D}-\mathrm{H} \cdots \mathrm{A}$ & $\mathrm{H} \cdots \mathrm{A}(\AA)$ & $\mathrm{D} \cdots \mathrm{A}(\AA)$ & $\mathrm{D}-\mathrm{H} \cdots \mathrm{A}\left(^{\circ}\right)$ \\
\hline $\mathrm{N} 6-\mathrm{H} 6 \mathrm{~A} \cdots \mathrm{S} 1$ & $2.630(6)$ & $3.318(5)$ & $135.8(5)$ \\
$\mathrm{N} 6-\mathrm{H} 6 \mathrm{~B} \cdots \mathrm{S} 1$ & $2.590(6)$ & $3.451(5)$ & $166.1(5)$ \\
$\mathrm{N} 3-\mathrm{H} 3 \mathrm{~A} \cdots \mathrm{S} 2$ & $2.849(6)$ & $3.415(4)$ & $126.5(5)$ \\
$\mathrm{N} 1-\mathrm{H} 1 \mathrm{~B} \cdots \mathrm{S} 2$ & $2.521(6)$ & $3.388(6)$ & $168.7(5)$ \\
$\mathrm{N} 1-\mathrm{H} 1 \mathrm{~A} \cdots \mathrm{C} 5$ & $2.630(6)$ & $3.272(6)$ & $126.8(5)$ \\
$\mathrm{N} 2-\mathrm{H} 2 \mathrm{~A} \cdots \mathrm{N} 5$ & $2.495(6)$ & $3.381(5)$ & $153.5(5)$ \\
\hline $\mathrm{N}-\mathrm{H}^{\delta+} \cdots{ }^{+\delta} \mathrm{H}-\mathrm{D}$ & $\mathrm{H} \cdots \mathrm{H}$ & & \\
\hline $\mathrm{N} 1-\mathrm{H} 1 \mathrm{~B} \cdots \mathrm{H} 6 \mathrm{~B}-\mathrm{N} 6$ & $2.345(4)$ & & \\
$\mathrm{N} 1-\mathrm{H} 1 \mathrm{~A} \cdots \mathrm{H} 52-\mathrm{C} 5$ & $2.272(9)$ & & \\
\hline
\end{tabular}

Table 3

$\mathrm{S} \cdots \mathrm{S}$ and $\mathrm{D}-\mathrm{H} \cdots \mathrm{A}$ hydrogen-bond geometry of $\left[\left(\mathrm{L}^{2 \cdot}\right) \mathrm{Cu}(\mathrm{SCN})\right](\mathrm{D}=\mathrm{C}, \mathrm{N}$ and $\mathrm{A}=\mathrm{S}, \mathrm{C}, \mathrm{N})$.

\begin{tabular}{llll}
\hline $\mathrm{D}-\mathrm{H} \cdots \mathrm{A}$ & $\mathrm{H} \cdots \mathrm{A}(\AA)$ & $\mathrm{D} \cdots \mathrm{A}(\AA)$ & $\mathrm{D}-\mathrm{H} \cdots \mathrm{A}\left({ }^{\circ}\right)$ \\
\hline $\mathrm{N} 6-\mathrm{H} 6 \mathrm{~B} \cdots \mathrm{S} 3$ & $2.571(1)$ & $3.379(3)$ & $174.9(1)$ \\
$\mathrm{N} 1-\mathrm{H} 1 \mathrm{~B} \cdots \mathrm{S} 3$ & $2.574(1)$ & $3.417(2)$ & $160.6(1)$ \\
$\mathrm{N} 1-\mathrm{H} 1 \mathrm{~A} \cdots \mathrm{S} 3$ & $2.678(1)$ & $3.526(2)$ & $162.2(1)$ \\
$\mathrm{C} 5-\mathrm{H} 51 \cdots \mathrm{S} 3$ & $2.998(1)$ & $3.919(3)$ & $157.2(1)$ \\
$\mathrm{N} 6-\mathrm{H} 6 \mathrm{~A} \cdots \mathrm{S} 1$ & $2.873(1)$ & $3.703(2)$ & $157.9(1)$ \\
$\mathrm{C} 3-\mathrm{H} 32 \cdots \mathrm{N} 6$ & $2.707(2)$ & $3.687(3)$ & $170.9(1)$ \\
\hline $\mathrm{S} \cdots \mathrm{S}$ & $\mathrm{S} \cdots \mathrm{S}(\AA)$ & & \\
\hline $\mathrm{S} 3 \cdots \mathrm{S} 3$ & $3.507(1)$ & & \\
\hline
\end{tabular}

The $\mathrm{H}_{2} \mathrm{~L}^{2}$ crystal structure is further stabilized by sulfur, carbon and nitrogen $(\mathrm{N}-\mathrm{H} \cdots \mathrm{A}$ with $A=S, C, N$ ) hydrogen interactions, where each unit $\mathrm{H}_{2} \mathrm{~L}^{2}$ shares with neighbouring molecules, four sulfur $\mathrm{N}-\mathrm{H} \cdots \mathrm{S}$ with distances range from $2.521(6)$ to $2.849(6) \AA$, with " $\mathrm{H} \cdots \mathrm{A}$ " length bonds of

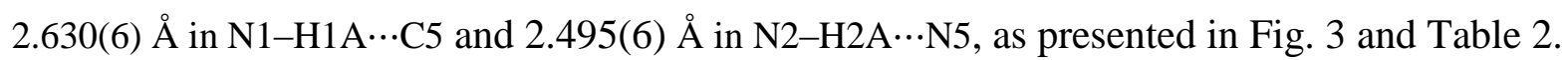




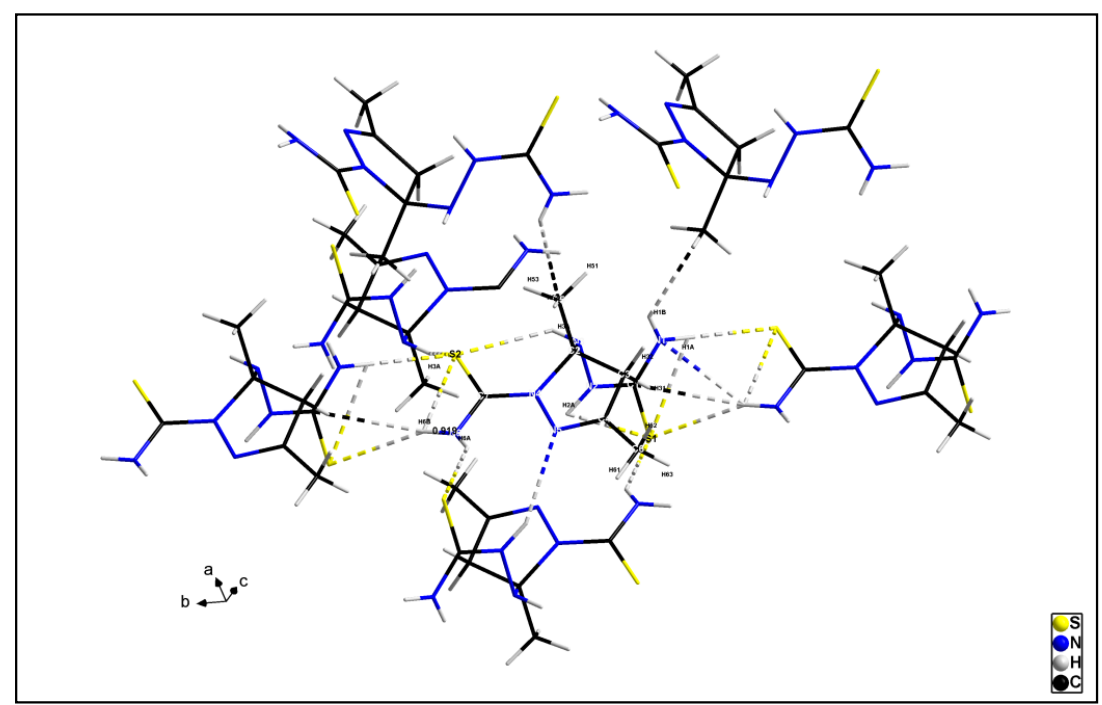

Fig. 3. $\mathrm{D}-\mathrm{H} \cdots \mathrm{A}(\mathrm{D}=\mathrm{C}, \mathrm{N}$ and $\mathrm{A}=\mathrm{S}, \mathrm{C}, \mathrm{N})$ hydrogen-interactions in crystal structure of $\mathrm{H}_{2} \mathrm{~L}^{2}$ ligand.

The $\mathrm{H}_{2} \mathrm{~L}^{2}$ crystal structure is further stabilized by sulfur, carbon and nitrogen $(\mathrm{N}-\mathrm{H} \cdots \mathrm{A}$ with $\mathrm{A}=\mathrm{S}, \mathrm{C}, \mathrm{N}$ ) hydrogen interactions, where each unit $\mathrm{H}_{2} \mathrm{~L}^{2}$ shares with neighbouring molecules, four sulfur $\mathrm{N}-\mathrm{H} \cdots \mathrm{S}$ with distances range from $2.511(6)$ to $2.886(6) \AA$, two carbon $\mathrm{N}-\mathrm{H} \cdots \mathrm{C}(2.791(6)$, 2.860(6) $\AA$ ) and two nitrogen $\mathrm{N}-\mathrm{H} \cdots \mathrm{N}$ (2.524(6), 2.690(6) $\AA$ ), as shown in Fig. 4.

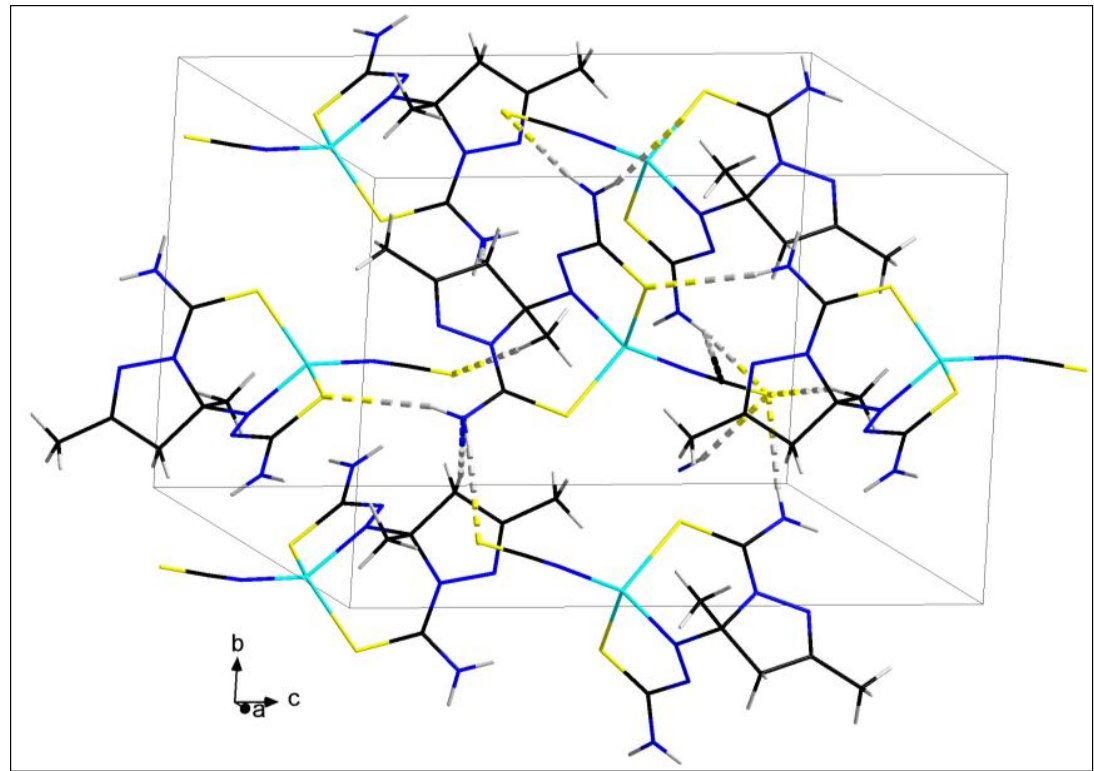

Fig. 4. Formation of the three-dimensional network involving $D-H \cdots A(D=C, N$ and $A=S, C, N)$ hydrogen-interactions in crystal structure of $\left[\left(\mathrm{L}^{2 \cdot}\right) \mathrm{Cu}(\mathrm{SCN})\right]$. 
It is noteworthy to point that, aside from the hydrogen bonds $\mathrm{D}-\mathrm{H} \cdots \mathrm{A}(\mathrm{D}=\mathrm{C}, \mathrm{N}$ and $\mathrm{A}=\mathrm{S}$, $\mathrm{C}, \mathrm{N}$ ), the $\mathrm{S} \cdots \mathrm{S}$ intermolecular interaction is also another useful organizing force in this supramolecular network. Further analysis of the crystal structure of $\left[\left(\mathrm{L}^{2 \cdot}\right) \mathrm{Cu}(\mathrm{SCN})\right]$ reveals short $\mathrm{S} \cdots \mathrm{S}$ contacts between SCN thiocyanate ligands of two neighbouring molecules, with a sulfur bond

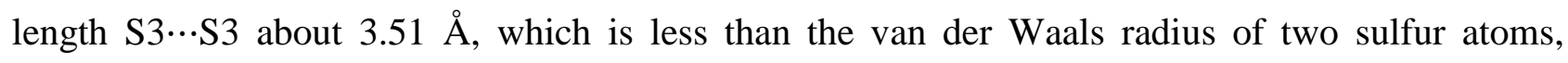
leading to the formation three-dimensional network, as indicated in Fig. 5. This structural feature with weak sulfur interactions is typical for related compounds [52-54]. It is also notable that the N7-C8 distance in the NCS thiocyanate ligand is extremely short $(\mathrm{N} 7-\mathrm{C} 8=1.145(3) \AA)$, presumably due to a chemical pressure caused by the $S 3 \cdots S 3$ contacts.

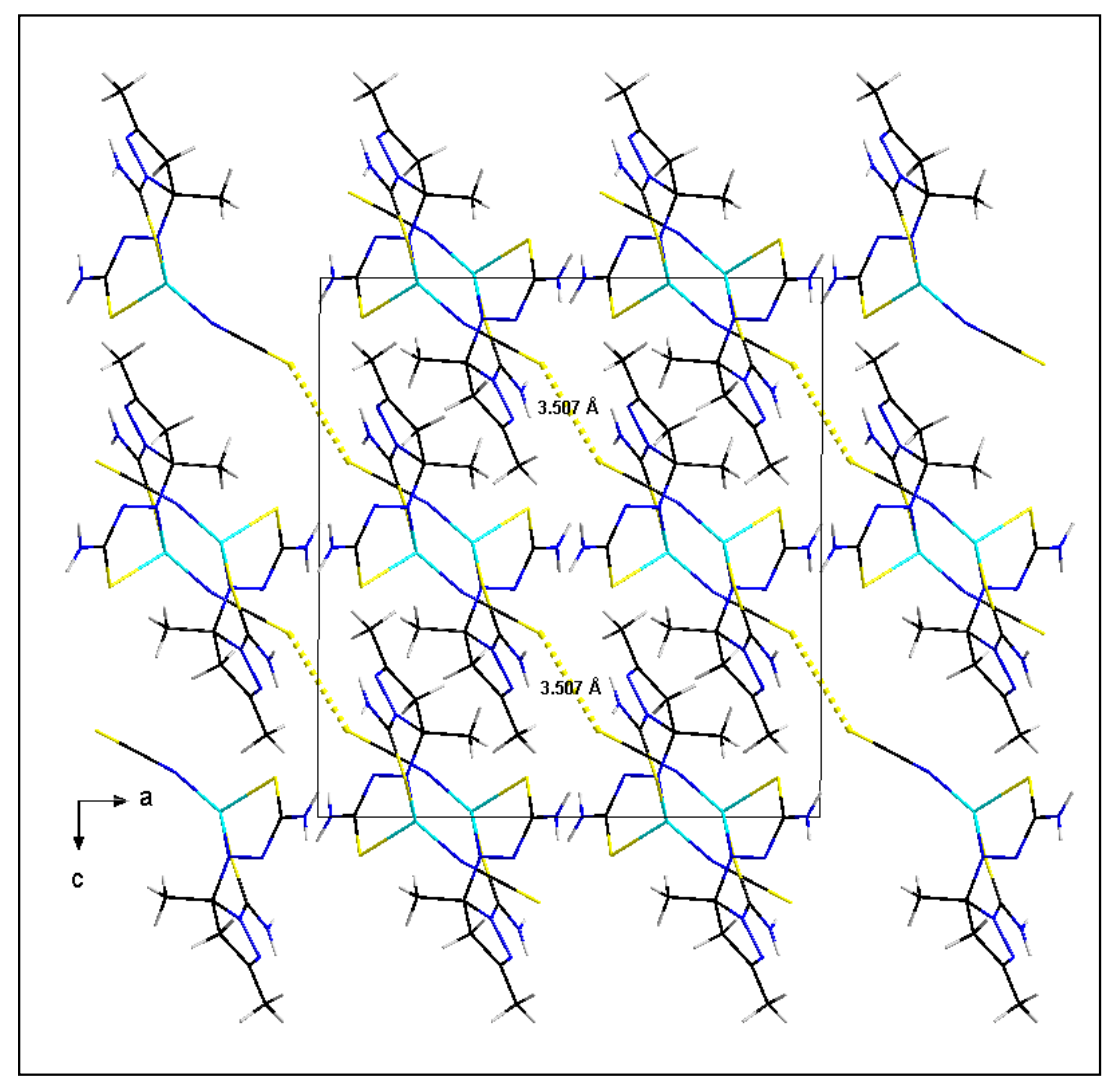

Fig. 5. View of the three-dimensional network involving $\mathrm{S} \cdots \mathrm{S}$ interactions in crystal structure of $\left[\left(\mathrm{L}^{2 \cdot}\right) \mathrm{Cu}(\mathrm{SCN})\right]$.

\subsection{Hirschfeld surface analysis}

A Hirschfeld surface analysis was performed to give insights into the important intermolecular interactions. These are normalized by van der Waals radii through a red-white-blue colour scheme, where the red spots denote close contacts of molecules. Two views of the Hirschfeld 
surface mapped over three dimensional $d_{\text {norm }}$ of the $\mathrm{H}_{2} \mathrm{~L}^{2}$ ligand and $\left[\left(\mathrm{L}^{2 \cdot}\right) \mathrm{Cu}(\mathrm{SCN})\right]$ complex are shown in Fig. 6. The red points represent closer contacts and negative $d_{\text {norm }}$ values on the surface corresponding to the $\mathrm{N}-\mathrm{H} \cdots \mathrm{S}$ interactions mentioned above $\left(\mathrm{N}-\mathrm{H} \cdots \mathrm{S} 1 / \mathrm{S} 2\right.$ for $\mathrm{H}_{2} \mathrm{~L}^{2}$ and $\mathrm{N}-\mathrm{H} \cdots \mathrm{S} 3$ for $\left[\left(\mathrm{L}^{2 \cdot}\right) \mathrm{Cu}(\mathrm{SCN})\right]$, while the other short intermolecular contacts appear as light-red spots $(\mathrm{N}-$ $\mathrm{H} \cdots \mathrm{N}$ and $\mathrm{N}-\mathrm{H} \cdots \mathrm{C}$ for the Ligand and $\mathrm{N}-\mathrm{H} \cdots \mathrm{S} 1$ and $\mathrm{S} 3 \cdots \mathrm{S} 3$ for the complex). In the view Hirshfeld surface mapped over the electrostatic potential in Fig. 7, the red and blue regions around the electronegative and electropositive atoms result from the polarization of charges about the acceptors and donors, respectively. $\mathrm{In}_{2} \mathrm{~L}^{2}$ ligand, the most negative sites are associated with the $\mathrm{S}$ atoms which undergoes electrophilic reactivity while the positive region over the protons of amine group indicates that these sites are susceptible for nucleophilic attack. The electrostatic potential calculated for the complex shows that the potential energy is positive over the organic cation and around the $\mathrm{NH}_{2}$ group while the negative potential energy described by red region around the sulphur atom of the thiocyanate group, resulting a global electrostatic attraction between $\mathrm{N}-\mathrm{H}$ and the $\mathrm{S}$ atoms of (NCS) group.

The two dimensional fingerprint plots in Figs. 8 and 9 for $\mathrm{H}_{2} \mathrm{~L}^{2}$ and $\left[\left(\mathrm{L}^{2 \cdot}\right) \mathrm{Cu}(\mathrm{SCN})\right]$, respectively, showed the intermolecular contacts and their percentage distributions on the Hirschfeld surface. All the relative percentage contributions to the overall Hirschfeld surface for ligand and complex are summarized in Table S7. The large red regions in Figs. 6 and 7 represent $\mathrm{H} \cdots \mathrm{S} / \mathrm{S} \cdots \mathrm{H}$ contacts, which are relevant in the $d_{\text {norm }}$ maps for ligand and complex. The $\mathrm{H} \cdots \mathrm{S} / \mathrm{S} \cdots \mathrm{H}$ contacts are similar for ligand and complex, with highest contributions of $31.6 \%$ and $32.6 \%$, respectively, of the total Hirschfeld surface area. In both ligand and complex, the $\mathrm{S} \cdots \mathrm{H}(20.1$ and 21.4\%, respectively) interactions make a larger contribution than the $\mathrm{H} \cdots \mathrm{S}(11.5$ and $11.2 \%$, respectively) interactions, indicating amine $\mathrm{H}$-atoms interacting with $\mathrm{S}$ atoms for the formation of the supramolecular assembly, is represented by the spikes in the bottom right and left region, $d_{\mathrm{e}}+$ $d_{\mathrm{i}} \approx 2.35 \AA$ (Fig. 8c and 9b). For the ligand, the $\mathrm{H} \cdots \mathrm{H}$ interactions appear in the middle of the scattered points in the fingerprint plots with a highest percentage contribution (53.6\%) (Fig. 8b), 
while their contribution in $\left[\left(\mathrm{L}^{2 \cdot}\right) \mathrm{Cu}(\mathrm{SCN})\right]$ are $27.2 \%$ (Fig. 9c), which underlines the importance of van der Waals interactions. For $\mathrm{H}_{2} \mathrm{~L}^{2}$, the small red spots represent $\mathrm{N} \cdots \mathrm{H} / \mathrm{H} \cdots \mathrm{N}$ and $\mathrm{C} \cdots \mathrm{H} / \mathrm{H} \cdots \mathrm{C}$ contacts attributed to $\mathrm{N}-\mathrm{H} \cdots \mathrm{N}$ and $\mathrm{N}-\mathrm{H} \cdots \mathrm{C}$ hydrogen bonds, which can also be seen in the fingerprint as a spikes at $d_{\mathrm{e}}+d_{\mathrm{i}} \approx 2.45 \AA$ (Fig. 8d) and $d_{\mathrm{e}}+d_{\mathrm{i}} \approx 2.60 \AA$ (Fig. 8e), respectively. The $\mathrm{C} \cdots \mathrm{H} / \mathrm{H} \cdots \mathrm{C}$ and $\mathrm{N} \cdots \mathrm{H} / \mathrm{H} \cdots \mathrm{N}$ interactions account for $13.5 \%$ and $11.9 \%$ in complex, respectively (Fig. 9d and 9e). These contacts stabilize the structure of complex. The S $\cdots S$ contacts have a contribution to the Hirschfeld surfaces of $2.9 \%$ in complex (Fig. 9h), revealing the S3*S3 interactions between the layers, with S-S distance $3.507 \AA$ which is less than the van der Waals, forming three-dimensional supramolecular network.

The Hirshfeld surfaces in the distortion coordination geometry formed by the $\mathrm{N}_{2} \mathrm{~S}_{2}$ about the copper (II) centre in $\left[\left(\mathrm{L}^{2 \cdot}\right) \mathrm{Cu}(\mathrm{SCN})\right]$ molecule that has been mapped to a normal surface are shown in Fig. 10. The dark red regions on the $d_{\text {norm }}$ surface for $\mathrm{Cu}$ show the contact between $\mathrm{N}-\mathrm{Cu}$ and $\mathrm{Cu} \cdots \mathrm{S}$. The Hirshfeld surfaces of the $\mathrm{Cu}^{2+}$ ion is much more concave towards the bond directions defined by the $\mathrm{N}$ atom of the thiocyanate group than those associated with coordination towards the $\mathrm{N}$ and $\mathrm{S}$ atoms (Figs. 10a and 10b). Although the covalent bonds with the sulfur and nitrogen atoms are dominant. The $\mathrm{Cu}$ atom has up to $49.7 \%$ of the contacts from the $\mathrm{N}-\mathrm{Cu}$ interaction on the Hirshfeld surface (the pair of aligned red points at different inclinations from $d_{\mathrm{e}}+d_{\mathrm{i}} \approx 2.0 \AA$ ) followed by $29.6 \%$ of the contacts from the $\mathrm{S}-\mathrm{Cu}$ coordinates $\left(d_{\mathrm{e}}+d_{\mathrm{i}} \approx 2.2 \AA\right)$.

The Hirshfeld surface analysis confirms the importance of $\mathrm{H}$ atoms contacts in estabilishing the packing. The large number of $\mathrm{H} \cdots \mathrm{H}, \mathrm{S} \cdots \mathrm{H} / \mathrm{H} \cdots \mathrm{S}, \mathrm{N} \cdots \mathrm{H} / \mathrm{H} \cdots \mathrm{N}$ and $\mathrm{C} \cdots \mathrm{H} / \mathrm{H} \cdots \mathrm{C}$ interactions suggest that van der Waals interactions and hydrogen bonding play dominant role in stabilizing the lattice of the ligand and complex structures, revealing also different packing modes. The HS of the metal centre differentiates relatively strong bonds from weaker contacts taking place within the interaction sphere. 

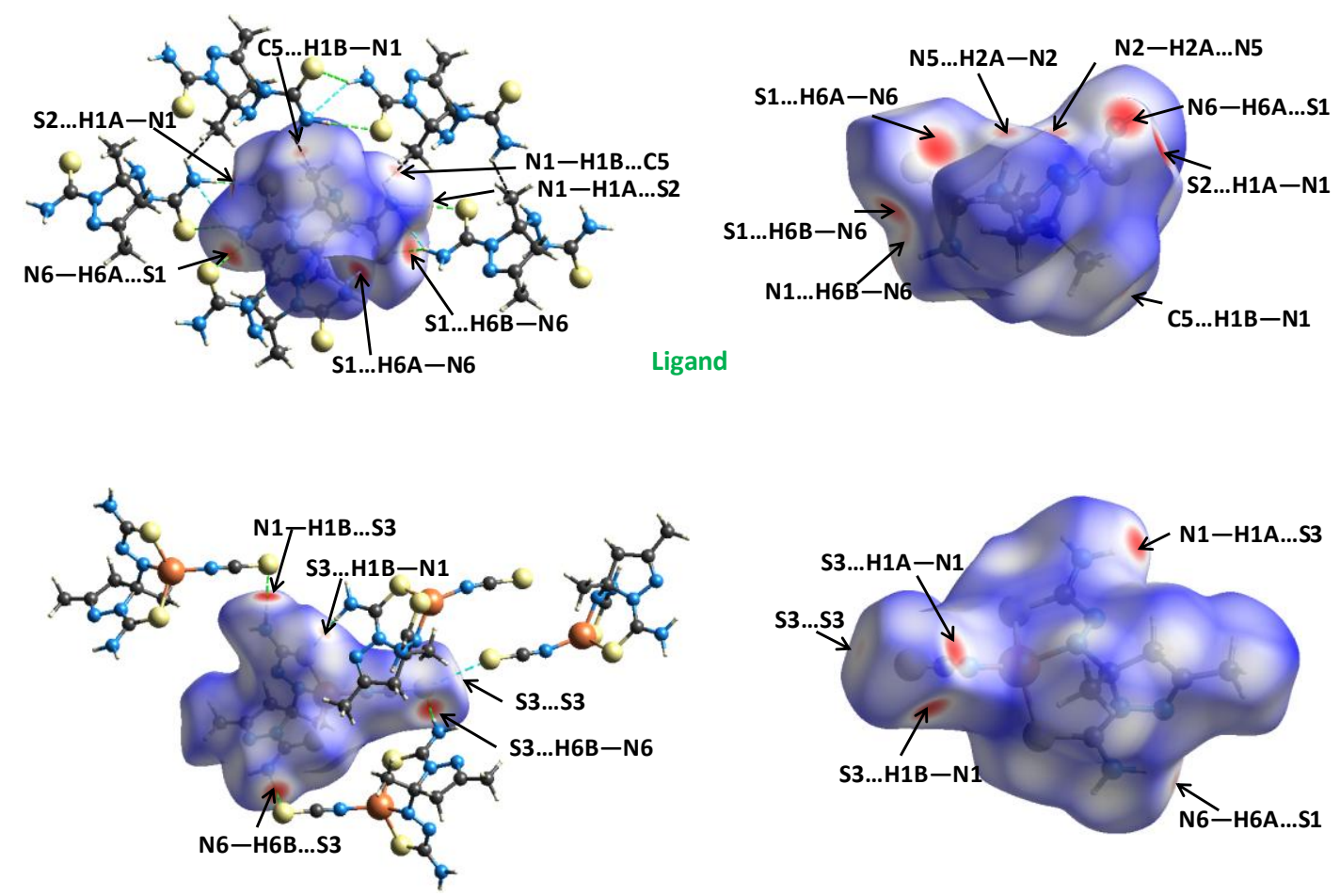

Complex

Fig. 6. Hirshfeld surface of $\mathrm{H}_{2} \mathrm{~L}^{2}$ ligand mapped over $d_{\text {norm }}$, showing short interatomic $\mathrm{N}-\mathrm{H} \cdots \mathrm{S}, \mathrm{N}-\mathrm{H} \cdots \mathrm{N}$ and $\mathrm{C}-\mathrm{H} \cdots \mathrm{N}$ contacts by dashed lines and Hirshfeld surface of $\left[\left(\mathrm{L}^{2 \cdot}\right) \mathrm{Cu}(\mathrm{SCN})\right]$ complex mapped over $d_{\text {norm }}$, showing short interatomic $\mathrm{N}-\mathrm{H} \cdots \mathrm{S}$ and $\mathrm{S} \cdots \mathrm{S}$ contacts by dashed lines.
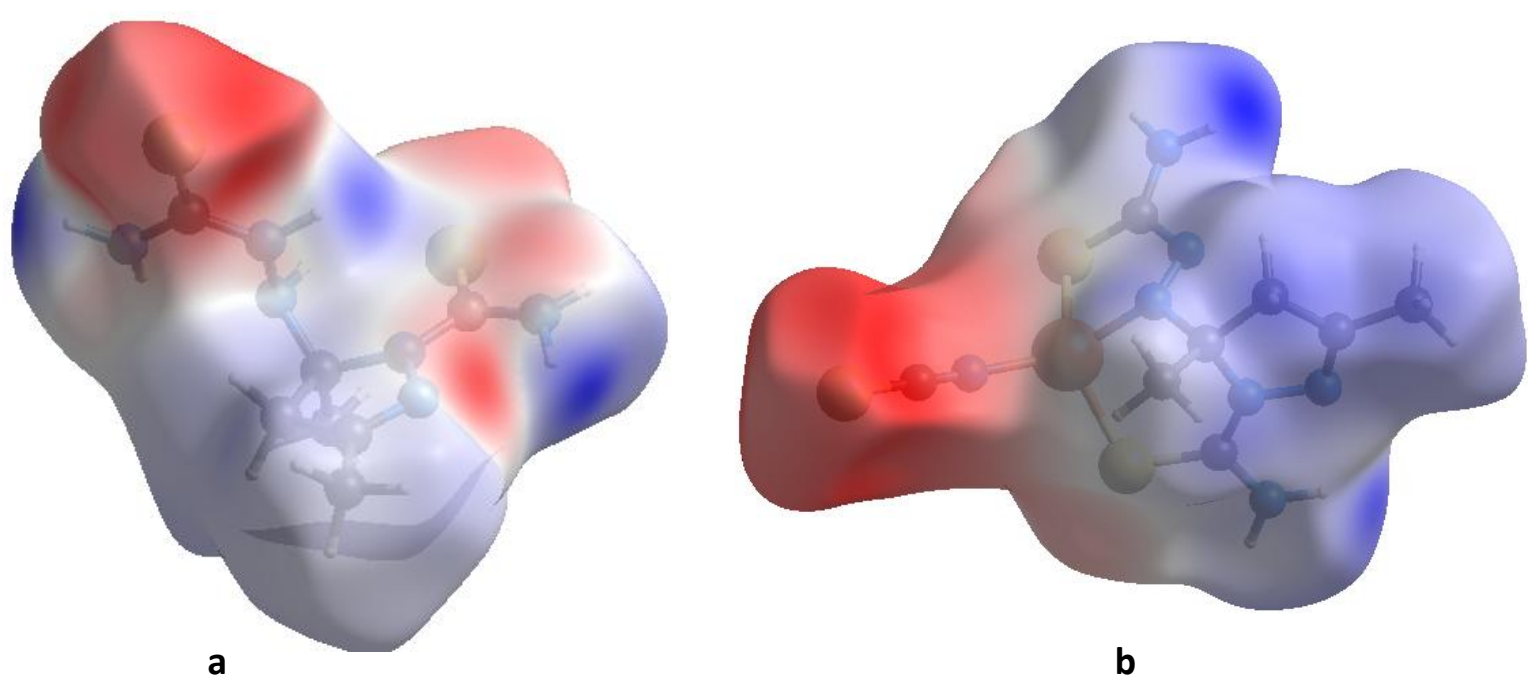

Fig. 7. Electrostatic potential mapped over the Hirshfeld surfaces of the (a) $\mathrm{H}_{2} \mathrm{~L}^{2}$ ligand and (b) $\left[\left(\mathrm{L}^{2 \cdot}\right) \mathrm{Cu}(\mathrm{SCN})\right]$ complex. 


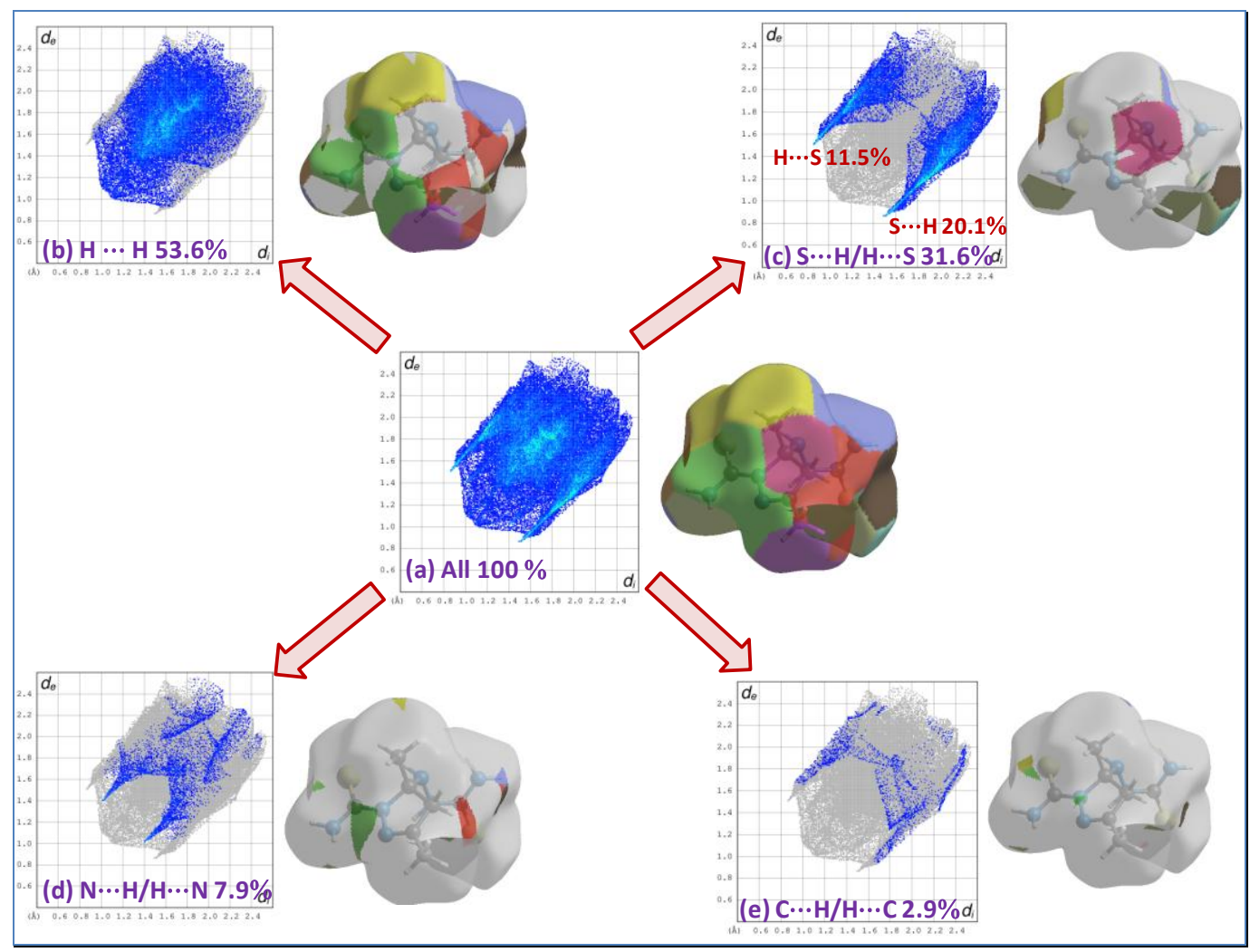

Fig. 8. The two-dimensional fingerprint plot for $\mathrm{H}_{2} \mathrm{~L}^{2}$ ligand, and the fingerprint plots delineated into (b) $\mathrm{H} \cdots \mathrm{H}$, (c) $\mathrm{S} \cdots \mathrm{H} / \mathrm{H} \cdots \mathrm{S}$, (d) $\mathrm{N} \cdots \mathrm{H} / \mathrm{H} \cdots \mathrm{N}$ and (e) $\mathrm{C} \cdots \mathrm{H} / \mathrm{H} \cdots \mathrm{C}$. 


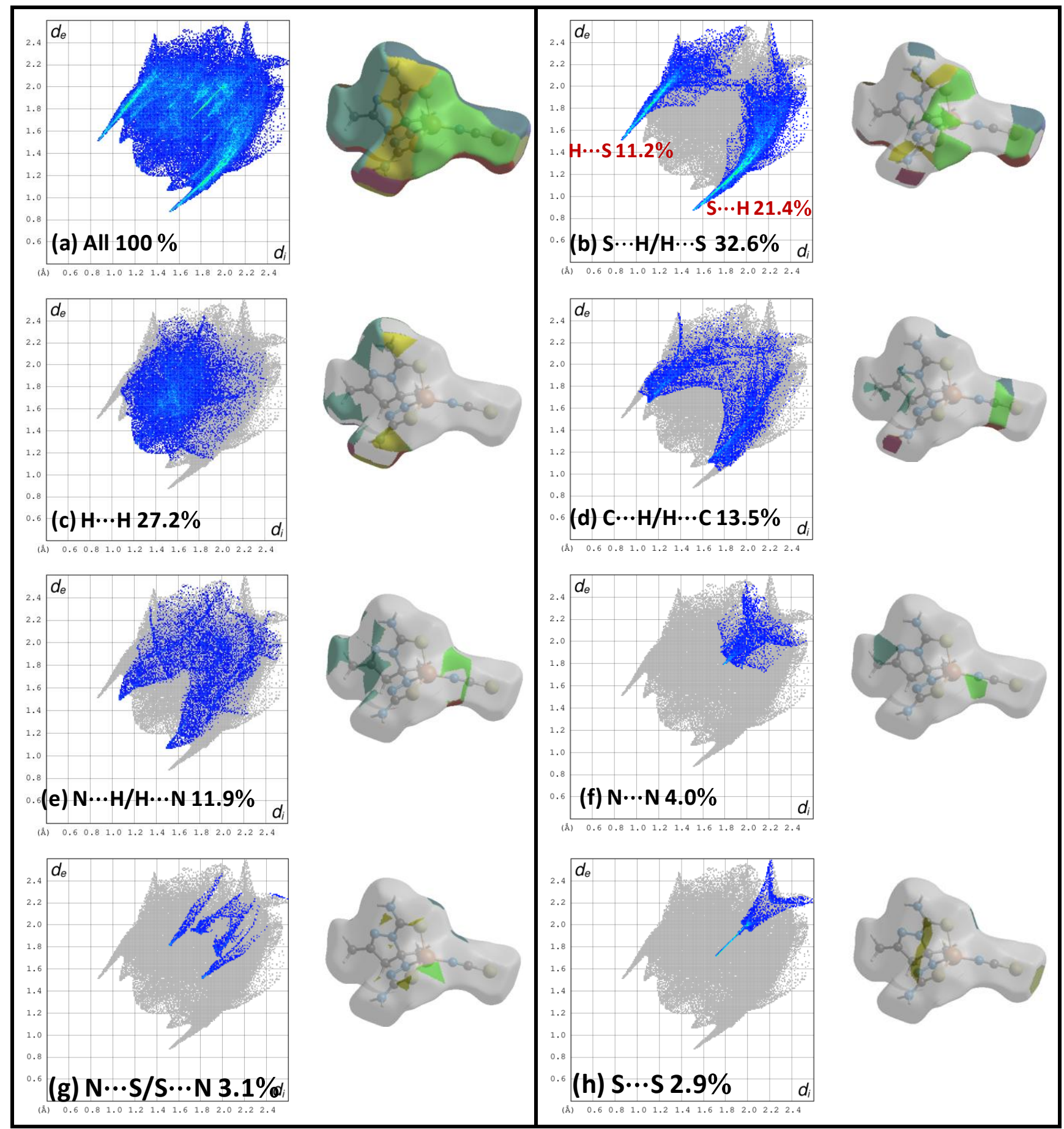

Fig. 9. (a) The two-dimensional fingerprint plot for $\left[\left(\mathrm{L}^{2 \cdot}\right) \mathrm{Cu}(\mathrm{SCN})\right]$ complex, and the fingerprint plots delineated into (b) $\mathrm{S} \cdots \mathrm{H} / \mathrm{H} \cdots \mathrm{S}$, (c) $\mathrm{H} \cdots \mathrm{H}$, (d) $\mathrm{C} \cdots \mathrm{H} / \mathrm{H} \cdots \mathrm{C}$, (e) $\mathrm{N} \cdots \mathrm{H} / \mathrm{H} \cdots \mathrm{N}$, (f) $\mathrm{N} \cdots \mathrm{N}$, (g) $\mathrm{N} \cdots \mathrm{S} / \mathrm{S} \cdots \mathrm{N}$ and (h) S $\cdots$ S contacts. 

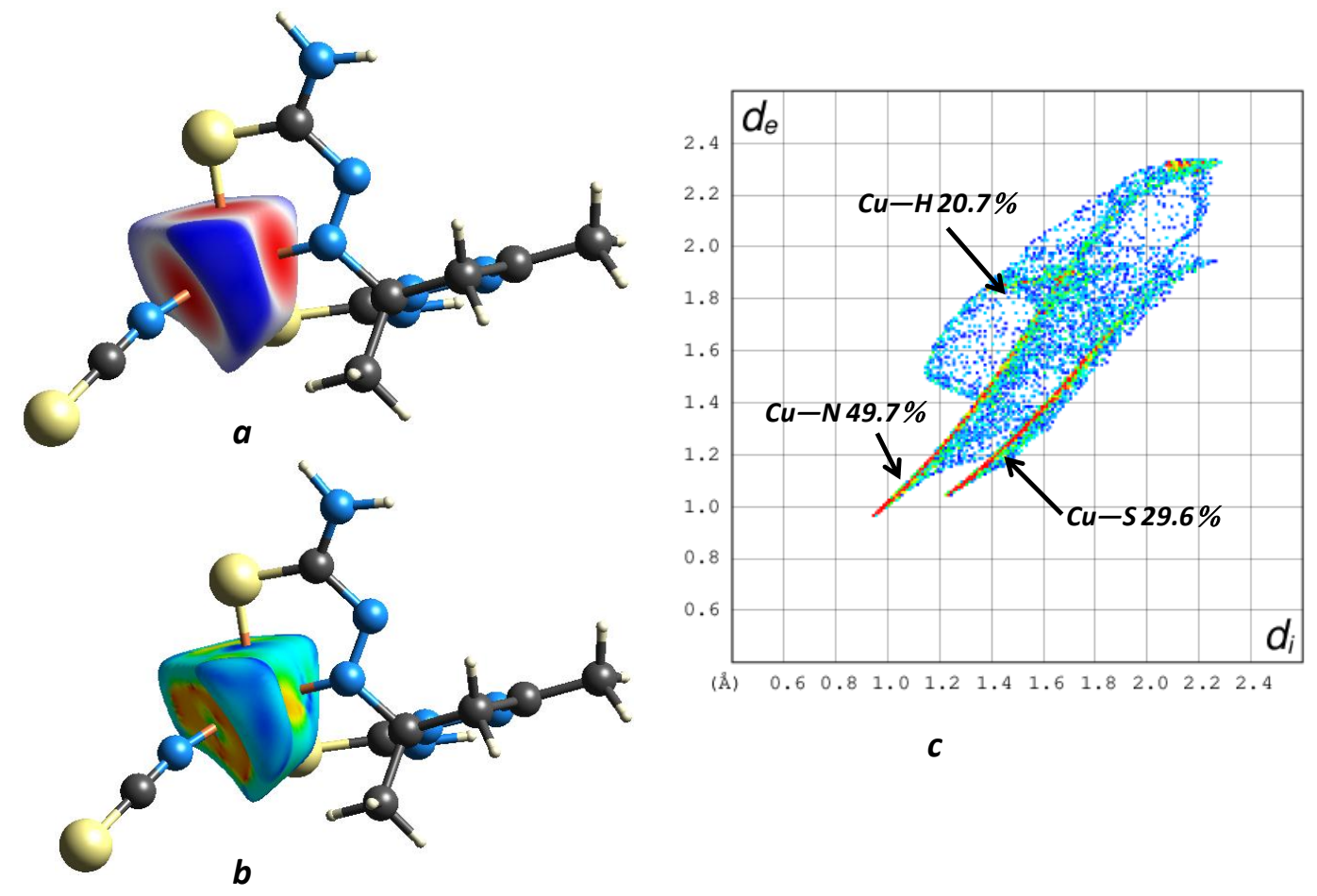

C

Fig. 10. Atomic Hirshfeld surface of copper in $\left[\left(\mathrm{L}^{2 \cdot}\right) \mathrm{Cu}(\mathrm{SCN})\right]$ complex with the descriptor (a) $d_{\text {norm }}$, (b) shape index mapped onto the surfaces and (c) corresponding fingerprint plot for the metallic centre.

\subsection{Spectroscopy studies}

\subsubsection{Ultraviolet-visible spectroscopy}

The electronic spectra of $\mathrm{H}_{2} \mathrm{~L}^{2}$ ligand and $\left[\left(\mathrm{L}^{2 \cdot}\right) \mathrm{Cu}(\mathrm{SCN})\right]$ complex have been measured in the range 250-800 $\mathrm{nm}$ and are shown in Fig. S1. The absorption maxima with the corresponding extinction coefficients are given in Table 4. In the UV region the presence of the organic ligand is confirmed by a very intense peak at $\lambda_{\max }, \mathrm{nm}\left(\varepsilon_{\max }, \mathrm{M}^{-1} \mathrm{~cm}^{-1}\right) 268(25039) \mathrm{nm}$ with a shoulder at $280(14856) \mathrm{nm}$, comparable to those of the free ligand at 266(24322) and 276(22052) $\mathrm{nm}$ and may be assigned to intra-ligand transitions $\pi-\pi^{*}$ and $n-\pi^{*}$ respectively [55]. Moreover, for the copper complex, the spectrum reveals two broad lower intensity transitions at $376 \mathrm{~nm}(2831)$ and $465 \mathrm{~nm}$ (2366). These bands could be attributed to a combination of charge transfer absorptions in the $\mathrm{Cu}^{\mathrm{II}}$ complex $[12,19,55]$. In addition, the spectrum shows a weak broad absorption attributable to $d-d$ transition at $717\left(1822 \mathrm{M}^{-1} \mathrm{~cm}^{-1}\right) \mathrm{nm}$, for a $\mathrm{Cu}(\mathrm{II})$ ion $\mathrm{d}^{9}$ in tetrahedral geometry [56]. 
Table 4

Assignments of the UV-Vis bands of $\mathrm{H}_{2} \mathrm{~L}^{2}\left(10^{-4} \mathrm{M}\right)$ and $\left[\left(\mathrm{L}^{2 \cdot}\right) \mathrm{Cu}(\mathrm{SCN})\right]$ complex $\left(1.510^{-4} \mathrm{M}\right)$ in DMF.

\begin{tabular}{ccccc}
\hline \multirow{2}{*}{ Compound } & \multicolumn{4}{c}{$\lambda_{\max }, \mathrm{nm}\left(\varepsilon_{\max }, \mathrm{M}^{-1} \mathrm{~cm}^{-1}\right)$} \\
\cline { 2 - 4 } & $\pi-\pi^{*}$ & $n-\pi^{*}$ & Charge transfer & $d-d$ \\
\hline $\mathrm{H}_{2} \mathrm{~L}^{2}$ & $266(24322)$ & $276(22052)$ & - & - \\
\hline$\left[\left(\mathrm{L}^{2 \cdot}\right) \mathrm{Cu}(\mathrm{SCN})\right]$ & $268(25039)$ & $280(14856)$ & $376(2831) ; 465(2366)$ & $717(1822)$
\end{tabular}

\subsection{2. ${ }^{1} \mathrm{H}$ and ${ }^{13} \mathrm{C}$ NMR analysis}

The ${ }^{1} \mathrm{H}$ and ${ }^{13} \mathrm{C}$ NMR spectra of free ligand $\mathrm{H}_{2} \mathrm{~L}^{2}$ were recorded in DMSO- $d_{6}$ are given in Fig. 11. The ${ }^{1} \mathrm{H}$ NMR spectrum presents two groups of signals for each group of the predicted linear bis(thiosemicarbazone), indicating the asymmetry of the molecule which is in agreement with the pyrazolinic form.

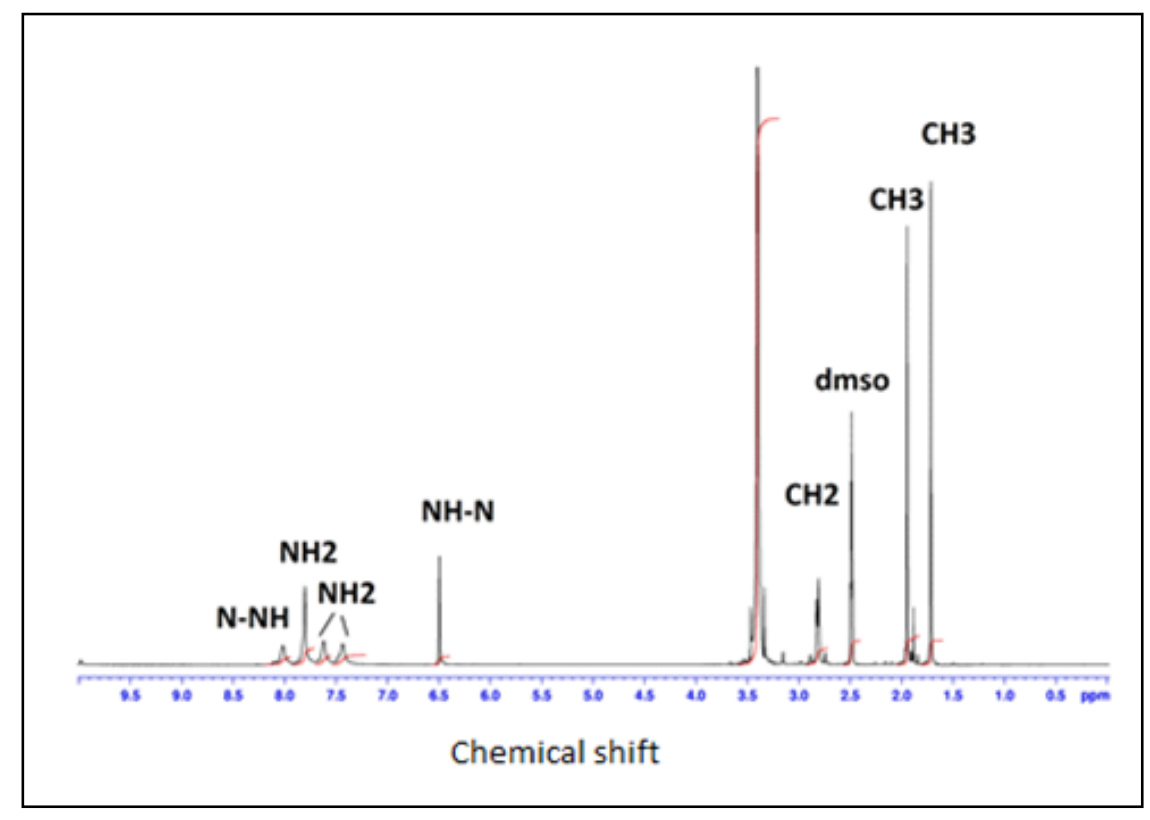




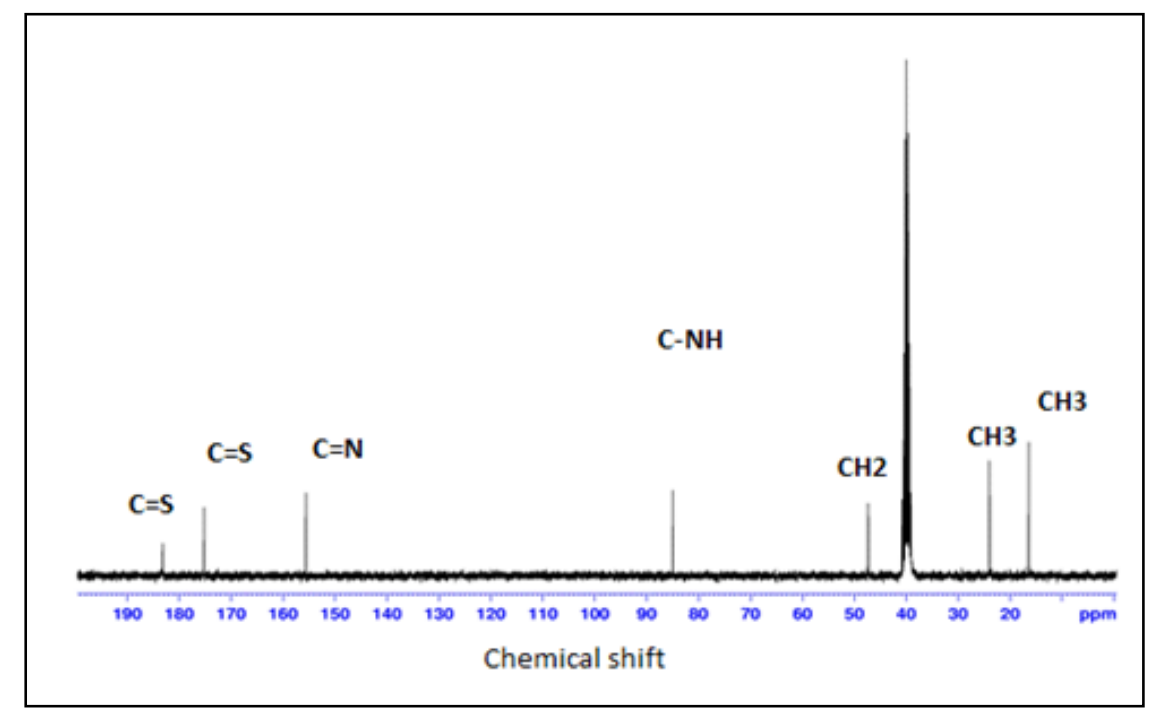

Fig. 11. ${ }^{1} \mathrm{H}$ and ${ }^{13} \mathrm{C}$ NMR spectra of $\mathrm{H}_{2} \mathrm{~L}^{2}$ recorded in DMSO- $d_{6}$.

Indeed, the two methyl groups are clearly distinguishable as two singlets at 1.71 and 1.94 ppm and the signal appearing as a quadruplet at $2.81 \mathrm{ppm}$, is assigned to $\mathrm{AB}$ system of methylene protons. The hydrazinic protons ( $\mathrm{HN}-\mathrm{NH})$ are exhibited as two singlets at 6.49 and $8.05 \mathrm{ppm}$ and, for thiocarbamoyl and thiosemicarbazide $\mathrm{NH}_{2}$ protons; the spectrum shows 3 singlets $(1 \mathrm{H}, 1 \mathrm{H}, 2 \mathrm{H})$ between 7.43 and $7.80 \mathrm{ppm}$. These values are in the range of those found for analogous pyrazoline $[13,22,23]$. The ${ }^{13} \mathrm{C}$ NMR spectrum in Fig. 11 displays 7 signals instead of the expected four for the symmetrical bis(thiosemicarbazone). The two carbons of methyl groups C6 and C5 appear at 16.33 and $23.92 \mathrm{ppm}$ respectively, the methylene carbon $\mathrm{C} 3$ at $47.29 \mathrm{ppm}$ and the signals at 84,88 and 155, $56 \mathrm{ppm}$ are attributed to $\mathrm{C} 2$ and $\mathrm{C} 4$ respectively. The two signals at 175.13 and $183.10 \mathrm{ppm}$ are assigned to the carbons of $\mathrm{C}=\mathrm{S}$ groups. The comparison of these data with those previously cited [12,23], suggests the pyrazoline form of the prepared ligand. NMR of $\left[\left(\mathrm{L}^{2 \bullet}\right) \mathrm{Cu}(\mathrm{SCN})\right]$ seems to indicate that the latter becomes paramagnetic once in solution. Indeed, the ${ }^{1} \mathrm{H}$ and ${ }^{13} \mathrm{C}$ NMR analyses of this copper complex performed in DMSO do not give the expected spectra for a diamagnetic complex. This behaviour was reported by Fox et al. [57] in a study of transition metalthiolate complexes which clearly showed that the investigated complex is diamagnetic as crystalline solid and becomes paramagnetic when dissolved in solvent. 


\subsubsection{FTIR spectroscopy}

The FTIR spectra of $\mathrm{H}_{2} \mathrm{~L}^{2}$ ligand and its complex are shown in Fig. $\mathrm{S} 2$ and the corresponding data are summarised in Table 5. The FTIR spectrum of the free ligand shows five broad bands between 3143 and $3423 \mathrm{~cm}^{-1}$, assignable to different $\mathrm{N}-\mathrm{H}$ vibrations $\left(v\left(\mathrm{NH}_{2}\right)\right.$ and $v(\mathrm{HN}-\mathrm{NH}))$ and an intense band at $1579 \mathrm{~cm}^{-1}$ assigned to $v(\mathrm{C}=\mathrm{N})$ pyrazoline cycle $[58,59]$. The FTIR spectrum doesn't display any band in the region $2550-2600 \mathrm{~cm}^{-1}$ range due to the S-H group, which indicates that ligand exists in thione form in solid state. In the FTIR spectrum of the title complex (Fig. S2), only 3 bands and one shoulder were observed for the $\mathrm{N}-\mathrm{H}$ vibrations, which means that ligand has been deprotonated and is coordinated in anionic form. Comparison between the spectra of $\mathrm{H}_{2} \mathrm{~L}^{2}$ ligand and $\left[\left(\mathrm{L}^{2 \bullet}\right) \mathrm{Cu}(\mathrm{SCN})\right]$ complex showed also a new sharp and strong signal at $2115 \mathrm{~cm}^{-1}$ attributed to the stretching vibration $v(\mathrm{CN})$ of thiocyanate group; a similar frequency was observed in a $\mathrm{Cu}$ complexes with $\mathrm{SCN}^{-}$ion coordinated to the metal via $\mathrm{N}$ atom $[60,61]$.

\section{Table 5}

FTIR data $\left(\mathrm{cm}^{-1}\right)$ of $\mathrm{H}_{2} \mathrm{~L}^{2}$ ligand and its complex $\left[\left(\mathrm{L}^{2 \cdot}\right) \mathrm{Cu}(\mathrm{SCN})\right]$.

\begin{tabular}{ccccc}
\hline Compound & $v(\mathrm{C}=\mathrm{N})_{\text {pyrazoline }}$ & $v(\mathrm{CN})_{\text {thiocyanate }}$ & $v\left(\mathrm{NH}_{2}\right)$ & $v(\mathrm{~N}-\mathrm{H})$ \\
\hline $\mathrm{H}_{2} \mathrm{~L}^{2}$ & $1579(s)$ & - & $3143(m) ; 3193(m) ;$ & $3423(\mathrm{~m})$ \\
& & & $3232(m) ; 3302(w)$ & \\
\hline $\mathrm{CuL}^{2} \mathrm{SCN}$ & $1598(s)$ & $2115(\mathrm{~s})$ & $3138(m) ; 3152(\mathrm{~m})$ & - \\
& & & $3243(\mathrm{~m}) ; 3376(\mathrm{~m})$ & \\
\hline
\end{tabular}

$w=$ weak, $m=$ medium,$s=$ strong

\subsubsection{Raman spectroscopy}

Fig. S3 shows the Raman spectra of $\mathrm{H}_{2} \mathrm{~L}^{2}$ ligand and its complex [( $\left.\left.\mathrm{L}^{2 \cdot}\right) \mathrm{Cu}(\mathrm{SCN})\right]$. The spectra of $\mathrm{H}_{2} \mathrm{~L}^{2}$ and its complex are clearly very different suggesting a strong interaction/link between $\mathrm{Cu}$ and the ligand, leading to a strong perturbation of all the ligand bonds. Some interesting features can be extracted. In the free ligand spectrum, the band at $1054 \mathrm{~cm}^{-1}$ can be attributed to the $\mathrm{C}-\mathrm{S}$ vibration [62]. In the complex spectrum, it can be suggested that this band is shifted down to 
$978 \mathrm{~cm}^{-1}$ due to the $\mathrm{S}-\mathrm{Cu}$ link. The very weak band at $2110 \mathrm{~cm}^{-1}$ observed in the complex spectrum can be attributed to $\mathrm{NCS}^{-}$anions [63].

\subsection{Thermal decomposition study}

The thermogravimetric study was carried out under air from room temperature up to $800^{\circ} \mathrm{C}$, in order to examine the thermal behaviour of the ligand and its copper complex and the obtained thermograms of $\mathrm{H}_{2} \mathrm{~L}^{2}$ ligand and its complex $\left[\left(\mathrm{L}^{2 \cdot}\right) \mathrm{Cu}(\mathrm{SCN})\right]$ are given in Figs. S4-S5. As shown in Fig. S4, the TG curve of $\left[\left(\mathrm{L}^{2 \cdot}\right) \mathrm{Cu}(\mathrm{SCN})\right]$ indicates that the copper complex is not decomposed up to $190^{\circ} \mathrm{C}$ and then gradual decomposition occurs in three successive steps within the temperature range $191{ }^{\circ} \mathrm{C}-741{ }^{\circ} \mathrm{C}$. The three stages with a total mass loss of $73.31 \%$ are attributed to the successive decomposition of the organic ligand and the thiocyanate ion from the copper complex. The first weight loss (observed $30.90 \%$; calcd. $31.46 \%$ ), between 191 and $386^{\circ} \mathrm{C}$, is associated with the release of the pyrazole cycle part linked to the aminothiocarbonyl group, after dissociation of C4-C3 and C2-N4 bonds (Fig. 1b). The second step $\left(386{ }^{\circ} \mathrm{C}-488^{\circ} \mathrm{C}\right)$ is complying with the loss (observed $31.19 \%$; calcd. $30.92 \%$ ) of the remaining entity of pyrazole cycle (without $\mathrm{NH}_{2}$ group) and the third step (observed $11.22 \%$; calcd. $11.75 \%$ ), between 618 and $741^{\circ} \mathrm{C}$, can be attributed to the degradation of thiocyanate and removal of the last part of the organic ligand with probably the formation of $\mathrm{CuS}$ as the final residue at $741{ }^{\circ} \mathrm{C}$ (observed $26.69 \%$; calcd. $26.12 \%$ ). In the case of the free $\mathrm{H}_{2} \mathrm{~L}^{2}$ ligand, the inspection of the obtained thermogram, given in Fig. S5, clearly indicated that, between 117 and $568{ }^{\circ} \mathrm{C}$, globally two big stages of decomposition (observed 69.54 $\%$ and $24.60 \%$ ) can be observed. The comparison with the theoretical values of the decomposition (calcd. $69.51 \%$ and $25.61 \%$ ), indicates that the total degradation of the free ligand is done in two stages starting with dissociation of the hydrazinic N2-N3 bond (Fig. 1a) and release of the cyclic moiety. At the end, no more noticeable weight loss is detected from $568{ }^{\circ} \mathrm{C}$ in agreement with the formation of carbon as a residual product (observed $4.50 \%$; calcd. $4.87 \%$ ). 


\subsection{Magnetic properties and Electronic structure calculations}

A preliminary magnetic study of $\left[\left(\mathrm{L}^{2 \bullet}\right) \mathrm{Cu}(\mathrm{SCN})\right]$ complex has been carried under an applied magnetic field of 500 Oe in temperature range 2-400 K and presented in Fig. 12. As shown in Fig. 12a, the thermal evolution of $\left[\left(\mathrm{L}^{2 \cdot}\right) \mathrm{Cu}(\mathrm{SCN})\right]$ magnetization, indicates that the complex adopts a diamagnetic comportment, which may be explain by a strong antiferromagnetic interaction between unpaired electrons due to a large overlap between magnetic orbitals and/or by the effect of the presence of the non-innocent ligand $\left(\mathrm{L}^{2 \cdot}\right)^{-}$.

In addition, the plot of magnetization versus applied field in the range $\pm 6 \mathrm{~T}$ presented in Fig. $12 \mathrm{~b}$, indicates that there is neither magnetic hysteresis loop nor saturation of magnetization up to 6 $\mathrm{T}$ a linear relationship between applied field and magnetization with a positive slope and very small value about $0.0045 \mu_{\mathrm{B}} / \mathrm{Cu}$ under $\mathrm{H}=6 \mathrm{~T}$ which is far below the expected saturation magnetisation of $M_{\mathrm{S}}=g S \mu_{\mathrm{B}}=1 \mu_{\mathrm{B}}$, assuming $g=2$, confirms a diamagnetic behaviour for $\mathrm{Cu}$ complex. To try finding explanation this magnetic evolution of studied complex, copper electronic structure have been evaluated using Density-functional theory (DFT) calculations.

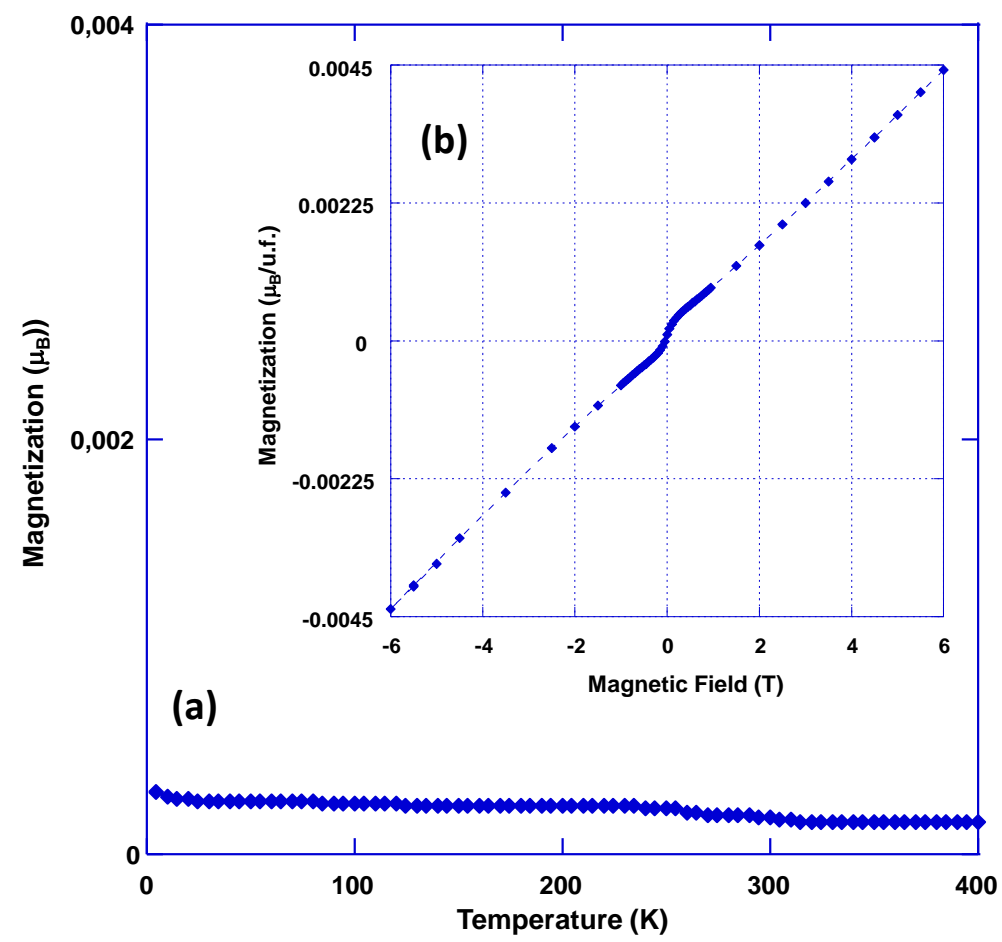

Fig. 12. (a) Temperature dependence of magnetic moment under 500 Oe and (b) Magnetization as a function of applied field at $2 \mathrm{~K}$, of $\left[\left(\mathrm{L}^{2 \cdot}\right) \mathrm{Cu}(\mathrm{SCN})\right]$ complex. 
Thus, the total Density of State (DOS) of our compound deduced from electronic structure calculations is reported in Fig. 13. Here, the Fermi level is taken as reference for energy. As seen, this DOS is perfectly symmetrical with respect to energy axis, pointing out that the system is not magnetically ordered. The total DOS is dominated by the resolved picks taking place in both occupied states at negative energies and unoccupied states localized at positive energies. Such features reveal the molecular character of the compound. The $l$-decomposed DOS of $\mathrm{d}$ and $\mathrm{s}$ likestates of $\mathrm{Cu}$ have been performed as well.

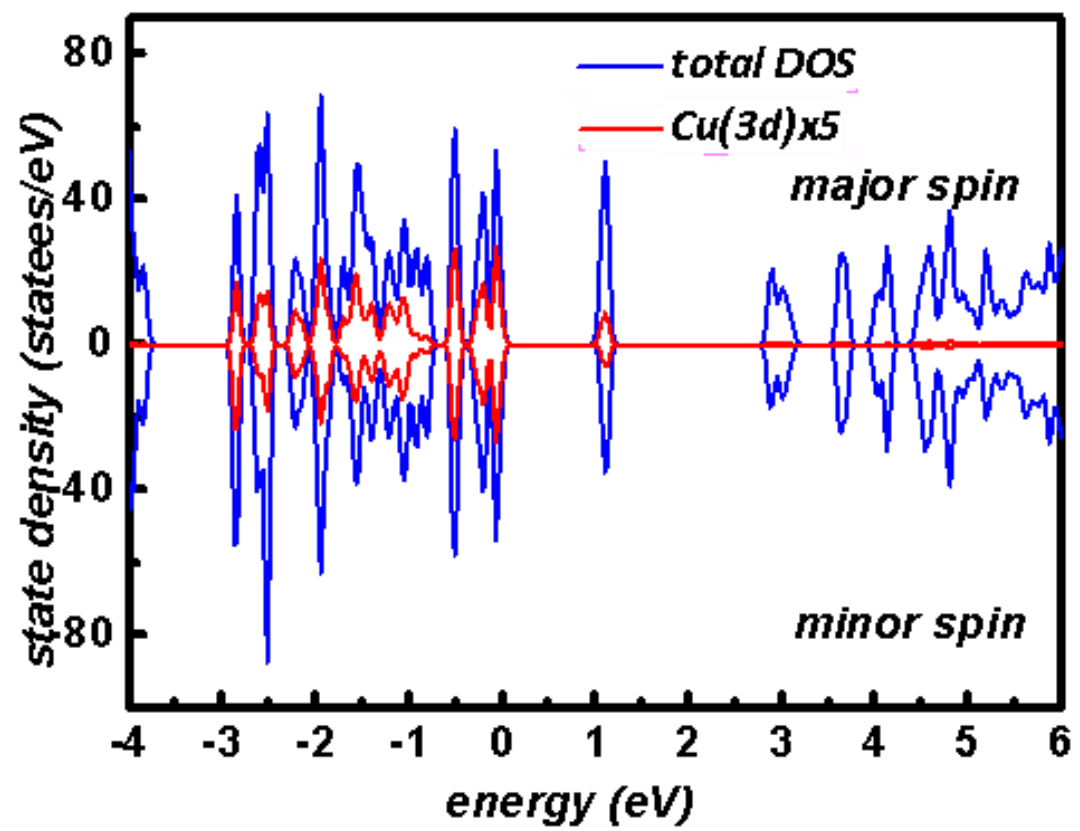

Fig. 13. Total $\mathrm{DOS}$ and d like-states of $\mathrm{Cu}$ of $\left[\left(\mathrm{L}^{2 \cdot}\right) \mathrm{Cu}(\mathrm{SCN})\right]$ from FLAPW calculations.

Further analysis gives evidence that the DOS of $\mathrm{Cu}$ is mainly from the $3 \mathrm{~d}$ band. In addition, it should be noticed that the DOS analysis points out to the absence of contributions from the s band of $\mathrm{Cu}$. The charge transfer of atoms is computed as well. Particularly, it reveals that the copper is in $\mathrm{Cu}^{2+}$ state loosing 2 electrons. Precisely, one electron is lost from $3 \mathrm{~d}$ band whereas the second one is lost from $4 \mathrm{~s}$ band leading to the electronic configuration transition from $\mathrm{Cu}\left(3 \mathrm{~d}^{10} 4 \mathrm{~s}^{1}\right)$ to $\mathrm{Cu}\left(3 \mathrm{~d}^{9} 4 \mathrm{~s}^{0}\right)$. Obviously the empty $4 \mathrm{~s}$ band does not contribute to the magnetism. Moreover, we underline that the odd number of electrons in the $3 \mathrm{~d}$ band does not induce a $\mathrm{Cu}$ magnetic state; since electron computation shows 4.5 electrons in $3 \mathrm{~d}$ up-spin band and 4.5 electrons in $3 \mathrm{~d}$ down-spin band. For all such reasons, we conclude that the $\mathrm{Cu}$ atom is in a diamagnetic state. In addition, no 
magnetic moment is observed on the remaining atoms and only a weak magnetic moment of 0.0044 $\mu \mathrm{B} / \mathrm{f}$.u. is revealed as contribution from the interstitial magnetism. In addition, copper magnetic moment about $0.0044 \mu \mathrm{B} / \mathrm{Cu}$, deduced from electronic structure calculations, should be confirmed by a second magnetic measurement $\mathrm{M}(\mathrm{H})$, with $\mathrm{Ms}$ about $0.0045 \mu \mathrm{B} / \mathrm{Cu}$ at maximum magnetic field of 6T. Similar behaviour has already been observed in different complexes as $\mathrm{Cu}(\mathrm{hfac})_{2}\left(\mathrm{NITmNO}_{2}\right)$ [64], $\mathrm{Cu}(\mathrm{hfac})_{2}(\mathrm{NITPh})_{2}[65]$ and $\mathrm{Cu}(\mathrm{hfac})_{2}(\mathrm{TMPNO})$ [66], where hfac $=$ hexafluoroacetylacetonate, $\mathrm{NITmNO}_{2}=2$-(3-nitrophenyl)-4,4,5,5-tetramethylimidazoline-1-oxyl-3oxide, NITPh = 2-phenyl-4,4,5,5-tetramethylimidazoline-1-oxyl-3-oxide and TMPNO = 2,2,6,6tetramethylpiperidine- $N$-oxyl. It is worth also mentioning that copper(II)-diamagnetic metal ion complexes may be interesting to explore the correlation of $d-d$ band position with structural parameters, as previously proposed by Kanda et al. [67] and explored later in other works [68-72].

\subsection{Antimicrobial activities}

The effect of $\mathrm{H}_{2} \mathrm{~L}^{2}$ and its complex $\left[\left(\mathrm{L}^{2 \cdot}\right) \mathrm{Cu}(\mathrm{SCN})\right]$ was assessed through the mycelial growth inhibition of 3 strains of $V$. dahliae and one strain of Fusarium oxysporum fsp. melonis. $V$. dahliae and F. oxysporum are the causal agent of wilt that affects several crops of economic interest [73,74]. Their effect on radial growth (Table 6, Fig. 14) showed that $\mathrm{H}_{2} \mathrm{~L}^{2}$ ligand did not exhibit any significant inhibition of mycelial growth whatever the concentration used and the fungal strain or species. However, its coordination with copper metal enhanced its activity against the strains SE and SJ of $V$. dahliae, given rise to $\mathrm{IC}_{50}$ values of 231 and $31 \mu \mathrm{g} \mathrm{mL}^{-1}$, respectively. The positive control thiophanate methyl caused a drastic inhibition of all the strains used, except for the strain SJ, which suggest that it is resistant to the thiophanate methyl fungicide. The elevated activity of $\left[\left(\mathrm{L}^{2 \cdot}\right) \mathrm{Cu}(\mathrm{SCN})\right]$ complex may be due to the synergetic effect of the ligand and the copper cation. The differential sensitivity of these fungal strains to the investigated complex could be explained by their different genetic background [75]. 


\section{Table 6}

In vitro inhibition of mycelial growth of Fusarium oxysporum fsp melonis and the strains $\mathrm{SH}$, SE and SJ of Verticillium dahliae.

\begin{tabular}{|c|c|c|c|c|c|}
\hline Compound & $\begin{array}{l}\text { Concentration } \\
\left(\mu \mathrm{g} \mathrm{mL}^{-1}\right)\end{array}$ & Vd SH (\%) & Vd SE (\%) & Vd SJ (\%) & FOM (\%) \\
\hline \multirow[t]{3}{*}{$\mathrm{H}_{2} \mathrm{~L}^{2}$} & 50 & $9 \pm 1^{a}$ & $23 \pm 3^{\mathrm{a}}$ & $14 \pm 9^{\mathrm{a}}$ & $6 \pm 3^{a}$ \\
\hline & 100 & $14 \pm 3^{\mathrm{a}}$ & $27 \pm 3^{a}$ & $18 \pm 6^{a}$ & $10 \pm 4^{\mathrm{a}}$ \\
\hline & 200 & $16 \pm 3^{a}$ & $29 \pm 4^{a}$ & $25 \pm 10^{\mathrm{a}}$ & $13 \pm 3^{a}$ \\
\hline \multirow[t]{3}{*}[(\mathrm{L}^{2\cdot})\mathrm{Cu}(\mathrm{SCN})]{} & 50 & $14 \pm 2^{\mathrm{a}}$ & $16 \pm 3^{\mathrm{a}}$ & $56 \pm 2^{b}$ & $10 \pm 2^{\mathrm{a}}$ \\
\hline & 100 & $15 \pm 3^{\mathrm{a}}$ & $22 \pm 7^{a}$ & $65 \pm 8^{\mathrm{b}}$ & $13 \pm 4^{\mathrm{a}}$ \\
\hline & 200 & $17 \pm 4^{\mathrm{a}}$ & $75 \pm 4^{b}$ & $86 \pm 2^{c}$ & $16 \pm 4^{\mathrm{a}}$ \\
\hline $\begin{array}{l}\text { Thiophanate } \\
\text { methyl }\end{array}$ & 200 & $86 \pm 2^{c}$ & $86 \pm 2^{c}$ & $32 \pm 5^{\mathrm{a}}$ & $81 \pm 3^{a}$ \\
\hline
\end{tabular}
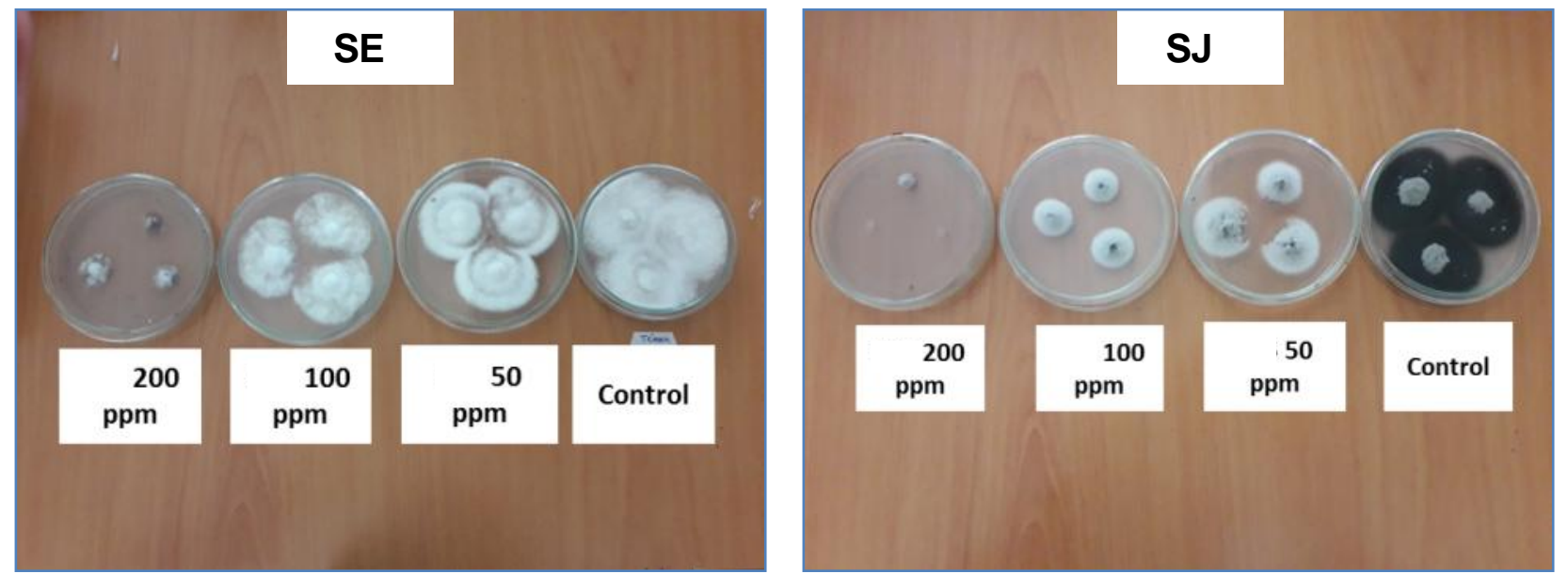

Fig. 14. Photos showing antifungal activity of $\left[\left(\mathrm{L}^{2 \cdot}\right) \mathrm{Cu}(\mathrm{SCN})\right]$ complex against the strains $\mathrm{SE}$ and $\mathrm{SJ}$ of Verticillium dahliae.

Pyrazole derivatives possess a wide range of biological activities, including antibacterial activity [76]. Their activities rely on the inhibition of DNA gyrase and topoisomerase [77]. However, their efficacy has been proved against Gram+ bacteria since they have only an outer peptidoglycan, which is not an effective permeability barrier conversely to Gram- bacteria possessing an outer phospholipidic membrane and lipopolysaccharide components. In this study we evaluated the effect of these pyrazolic derivatives against several phytopathogenic bacteria of 
economic interest such as A. tumefaciens, which is the causal agent of crown gall disease [78]. They showed moderate inhibition of the strains A281, C58 and Ach5 and no significant difference was observed between the ligand and its complex when compared to the standard chloramphenicol (Fig. 15). Similar tendency was observed against two different Pseudomonas syringae pathovars, which are taxonomically related, but differ in pathology, virulence and symptoms development in various crops [79]. Among them, $P$. syringae pv. tabaci causes wild fire disease of tobacco, and $P$. syringae pv. syringae, a common epiphytic bacterium that causes diseases of various plants [80]. In this study, the growth of $P$. syringae pv. syringae was moderately inhibited by both $\mathrm{H}_{2} \mathrm{~L}^{2}$ and $\left[\left(\mathrm{L}^{2 \cdot}\right) \mathrm{Cu}(\mathrm{SCN})\right]$ conversely to $P$. syringae pv. tabaci, which was completely insensitive to both of them. The reason for different sensitivities between tested bacteria could be ascribed to the morphological difference between their exopolysaccharides (EPS) polymers, which form a capsule or slime layer around bacterial cells that may act as an effective permeability barrier [81].

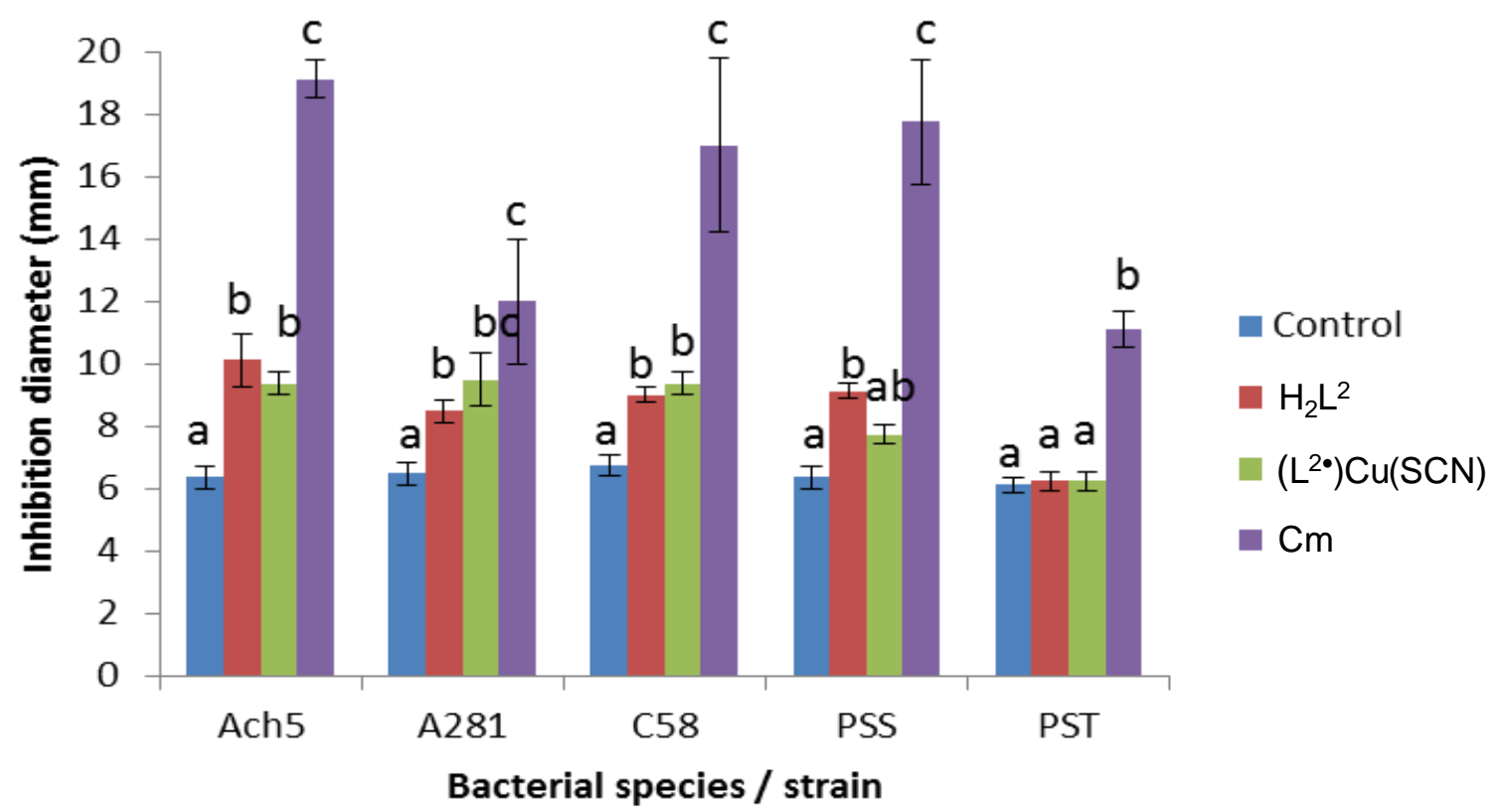

Fig. 15. Antibacterial activity of $\mathrm{H}_{2} \mathrm{~L}^{2}$ and $\left[\left(\mathrm{L}^{2 \cdot}\right) \mathrm{Cu}(\mathrm{SCN})\right]$ against the strains Ach5, A281 and $\mathrm{C} 58$ of Agrobacterium tumefaciens, Pseudomonas syringaepv. syringae (PSS) and Pseudomonas syringaepv. tabaci (PST). Data are means and confidence intervals from three replicates $(\alpha=5 \%)$. Inhibition diameter was recorded $48 \mathrm{~h}$ after incubation at $28{ }^{\circ} \mathrm{C}$ with sterile cellulose discs impregnated with $200 \mu \mathrm{g} \mathrm{ml}^{-1}$ of the two products or with $50 \mu \mathrm{g} \mathrm{ml}^{-1}$ of chloramphenicol antibiotic $(\mathrm{Cm})$ used as standard. Letters indicate significant differences according to Tukey HSD test $(P<0.55)$. 


\section{Conclusions}

The title complex $\left[\left(\mathrm{L}^{2 \cdot}\right) \mathrm{Cu}(\mathrm{SCN})\right]$ has been prepared by reaction of $\mathrm{H}_{2} \mathrm{~L}^{2}$ ligand and thiocyanate salt with copper acetates and has been fully characterized. Single-crystal X-ray diffraction reveals that the complex is a neutral monomer with copper in distorted tetrahedral environment and would be the result of a double deprotonation coupled with a monoelectronic oxidation. The ligand is mono anionic and remains in cyclic form and is coordinated as terdentate ligand (SNS). According to the magnetic study, the $\mathrm{Cu}$ atom in the complex is in a diamagnetic state. This behaviour can be explained by a strong antiferromagnetic coupling between the metal ion and the radical ligand, who suggests that $\left[\left(\mathrm{L}^{2 \cdot}\right) \mathrm{Cu}(\mathrm{SCN})\right]$ can be seen as a $\mathrm{Cu}^{\mathrm{II}}$-ligand radical type complex with $\left(\mathrm{L}^{2 \bullet}\right)^{-}$in mono anionic form. This study reinforces the notion of the noninnocence of the organic ligand. The $\left[\left(\mathrm{L}^{2 \cdot}\right) \mathrm{Cu}(\mathrm{SCN})\right]$ complex showed also elevated antifungal activity against various strains of phytopathogenic fungus suggesting its possible use as a fungicide in crop protection.

\section{Supplementary material}

CCDC 2022916 and CCDC 2022923 contain the supplementary crystallographic data for $\mathrm{H}_{2} \mathrm{~L}^{2}$ ligand and its complex $\left[\left(\mathrm{L}^{2 \cdot}\right) \mathrm{Cu}(\mathrm{SCN})\right]$. These data can be obtained free of charge via www.ccdc.cam.ac.uk/data_request/cif, or by emailing data_request@ccdc.cam. ac.uk, or by contacting the Cambridge Crystallographic Data Centre, 12 Union Road, Cambridge CB2 1EZ, UK; fax: +44 1223336033

\section{Acknowledgements}

The authors are greatly thankful to the CUR CA2D of Chouaib Doukkali University for its support and UCA-PARTNER for the use of the Bruker SC diffractometer. We thank Prof. V.B. Arion for giving us the $\mathrm{H}_{2} \mathrm{~L}^{1}$ ligand and Prof. M. Faize for his biologic assessment contribution. 


\section{References}

[1] C. Stefani, Z. Al-Eisawi, P. J. Jansson, D.S. Kalinowski, D.R. Richardson, J. Inorg. Biochem. 152 (2015) 20-37.

[2] D. Palanimuthu, S.V. Shinde, K. Somasundaram, A.G. Samuelson, J. Med. Chem. 56 (2013) 722-734.

[3] V.M. Leovac, V.I. Češljević, G. Argay, A. Kálmán, Bél. Ribár, J. Coord. Chem. 34 (1995) 357-364.

[4] A.K. Pramanik, Siddikuzzaman, D. Palanimuthu, K. Somasundaram, A.G. Samuelson, Bioconjug. Chem. 12 (2016) 2874-2885.

[5] S. Chandra, S. Raizada, M. Tyagi, A. Gautam, Bioinorg. Chem. Appl. 2007, Article ID 51483, 7 pp.

[6] R.I. Maurer, P.J. Blower, J.R. Dilworth, C.A. Reynolds, Y. Zheng, G.E.D. Mullen, J. Med. Chem. 45 (2002) 1420-1431.

[7] J.L.J. Dearling, J S. Lewis, G.E.D. Mullen, M.J. Welch, P.J. Blower, J. Biol. Inorg. Chem. 7 (2002) 249259.

[8] J.S. Lewis, T.L. Sharp, R. Laforest, Y. Fujibayashi, M.J. Welch, J. Nucl. Med. 42 (2001) 655-661.

[9] J.K. Lim, C.J. Mathias, M.A. Green, J. Med. Chem. 401 (1997) 132-136.

[10] M.A. Green, D.L. Klippenstein, J.R. Tennison, J. Nucl. Med. 29 (1988) 1549-1557.

[11] A.R. Cowley, J.R. Dilworth, P.S. Donnelly, A.D. Gee, J.M. Heslop, Dalton Trans. (2004) 2404-2412.

[12] S.C. Davies, M.C. Durrant, D.L. Hughes, A. Pezeshk, R.L. Richards, J. Chem. Res. 3 (2001) 100-103.

[13] J.K. Bilyj, M.J. Riley, P.V. Bernhardt, Dalton Trans. 47 (2018) 2018-2030.

[14] J.K. Bilyj, J.R. Harmer, P.V. Bernhardt, Eur. J. Inorg. Chem. 25 (2018) 4731-4741.

[15] S. Blanchard, F. Neese, E. Bothe, E. Bill, T. Weyhermüller, K. Wieghardt, Inorg. Chem. 44 (2005) 3636-3656.

[16] V.B. Arion, Coord. Chem. Rev. 387 (2019) 348-397.

[17] N.V. Gerbeleu, Y.A. Simonov, V.B. Arion, V.M. Leovac, K.I. Turta, K.M. Indrichan, D.I. Gradinaru, V.E. Zavodnik, T.I. Malinovski, Inorg. Chem. 31 (1992) 3264-3268.

[18] V.M. Leovac, L.S. Jovanovic, V.I. Cesljevic, L.J. Bjelica, N.J. Evic, Polyhedron, vol. (1992) 10291035.

[19] U. Knof, T. Weyhermuller, T. Wolter, K. Wieghardt, J. Chem. Soc., Chem. Commun. (1993) 726-728.

[20] M. Akbar Ali, P.V. Bernhardt, M.A. H. Brax, J. England, A.J. Farlow, G.R. Hanson, L. Len Yeng, A. Huq Mirza, K. Wieghardt, Inorg. Chem. 52 (2013) 1650-1657.

[21] C.N. O’Callaghan, D. Twomey, J. Chem. Soc. C (1967) 2400-2402.

[22] K.N. Zelenin, A.B. Tomchin, O.V. Solod, M.Y. Malov, Chem. Heterocycl. Compd. 22 (1986) 107-108.

[23] D.H. Hunter, C. McRoberts, J.J. Vittal, Can. J. Chem. 76 (1998) 522-524.

[24] T.I.A. Gerber, E. Hosten, O. Knoesen, P. Maye, J. Coord. Chem. 60 (2007) 2369-2375.

[25] P. Kulkarni, S. Padhye, E. Sinn, C. E. Anson, A.K. Powell, Inorg. Chim. Acta 332 (2002) 167-175.

[26] R.M.C. Brito, A.A. Batista, J. Ellena, E.E. Castellano, I.C.N. Diógenes, L.G. de França Lopes, J.R. de Sousa, I. de Sousa Moreira, Inorg. Chem. Commun. 10 (2007) 1515-1517.

[27] A. Espinosa, M. Sohail, M. Habib, K. Naveed, M. Saleem, H.U. Rehman, I. Hussain, A. Munawar, S. Ahmad, Polyhedron 90 (2015) 252-257.

[28] H.D. Bian, W. Gu, Q. Yu, S.P. Yan, D.Z Liao, Z.H Jiang, P. Cheng, Polyhedron 24 (2005) 2002-2008.

[29] S. Suckert, H. Terraschke, H. Reinsch, C. Näther, Inorg. Chim. Acta 461 (2017) 290-297.

[30] F.A. Mautner, C. Berger, R.C. Fischer, S.S. Massoud, R. Vicente, Polyhedron 141 (2018) 17-24.

[31] S. Chattaraj, A.K. Das, Spectrochim. Acta B 47 (1992) 675-680.

[32] M.R. Haque, J.H. Bradbury, 45 (199) 1459-1464.

[33] J. Hovinen, M. Lahti, J. Vilpo, 76 (1999) 1281-1282.

[34] M. Pollay, Am. J. Physiol. 210 (1966) 275-279.

[35] E. Saussereau, J.P. Goullé, C. Lacroix, J. Anal. Toxicol. 31 (2007) 383-387.

[36] N. Goi, K. Takagi, Y. Hirai, H. Harada, A. Ikari, Y. Terashima, N. Kinae, M. Hiramatsu, K. Nakamura, T. Ono, J. Health Sci. 53 (2007) 161-169.

[37] J. Hovinen, R. Silvennoinen, J. Vilpo, Chem. Res. Toxicol. 11 (1998) 91-93. 
[38] Bruker, APEX2. Bruker AXS Inc., Madison, Wisconsin, USA, 2012.

[39] Bruker, SAINT. Bruker AXS Inc., Madison, Wisconsin, USA, 2012.

[40] Bruker, SADABS. Bruker AXS Inc., Madison, Wisconsin, USA, 2012.

[41] G.M. Sheldrick, Acta Cryst. C71 (2015) 3-8.

[42] M.A. Spackman, D. Jayatilaka, CrystEngComm 11 (2009) 19-32

[43] J.J. McKinnon, D. Jayatilaka, M.A. Spackman, Chem. Commun. (2007) 3814-3816.

[44] M.J. Turner, J.J. McKinnon, S.K. Wolff, D.J. Grimwood, P.R. Spackman, D. Jayatilaka, M.A. Spackman, CrystalExplorer17, The University of Western Australia, 2017.

[45] P. Blaha, K. Schwartz, G.K.H. Madsen, D. Kvasnicka, J. Luitz, WIEN2k, An Augmented Plane Wave plus Local Orbitals Program for Calculating Crystal Properties. Vienna University of Technology, Austria. ISBN 3-9501031-1-2.

[46] A. Smaili, N. Mazoir, LA. Rifai, T. Koussa, K. Makroum, A. Benharref, L. Faize, N. Alburquerque, L. Burgos, M. Belfaiza, M. Faize, Nat. Prod. Commun. 12 (2017) 331-336.

[47] S. Esserti, A. Smaili A, L.A. Rifai, T. Koussa, K. Makroum, M. Belfaiza, M. Kabil, L. Faize, L. Burgos, N. Alburquerque, M. Faize, J. Appl. Phycol. 29 (2017) 1081-1093.

[48] K. Brandenburg, K. Putz, Diamond, Ver.3.1, Crystal Impact GbR, Bonn, Germany, 2008.

[49]. S.K. Verma, R. Kadu, V.K. Singh, Inorg. Metal-Org. Nano-Metal Chem. 44 (2014) 441-448

[50] F.W.B. Einstein, J.S. Field, Acta Crystallogr. B 30 (1974) 2928-2930.

[51] H.-J. Lee, S. Jung, J.-Hyun Cha, D. Nam, W. Choe, D.-Y. Jung, J. Mol. Struct. 1204 (2020) 127478.

[52] M. Du, X.-J. Zhao, and Y. Wang, Dalton Trans. (2004) 2065-2072.

[53] M. Du, C.-P. Li, Inorg. Chim. Acta 359 (2006) 1690-1696.

[54] Y. Shuku, R. Suizu, K. Awaga, Os. Sato, CrystEngComm 11 (2009) 2065-2068.

[55] I.C. Mendes, J.P. Moreira, A.S. Mangrich, S.P. Balena, B.L. Rodrigues, H. Beraldo, Polyhedron 26 (2007) 3263-3270.

[56] S.C. Davies, M.C. Durrant, D.L. Hughes, A. Pezeshk, R.L. Richards, J. Chem. Res. 3 (2001) 100-103.

[57] D.C. Fox, A.T. Fiedler, H.L. Halfen, T.C. Brunold, J.A. Halfen, J. Am. Chem. Soc. 126 (2004) 7627763.

[58] M. Abid, A. Azam, Bioorg. Med. Chem. 13 (2005) 2213-2220.

[59] G.F. de Sousa, C.C. Gatto, I.S. Resck, V.M. Deflon, J. Chem. Crystallogr. 41 (2011) 401-408.

[60] H.C. Chang, F.C. Lo, W.C. Liu, T.H. Lin, W.F. Liaw, T.S. Kuo, W.Z. Lee, Inorg. Chem. 54 (2015) $5527-5533$.

[61] F. Rhoufal, A. Laachi,S. Guesmi, L. Jouffret, N. Sergent, S. Obbade, M. Akkurt,and F. Bentiss, Chemistry Select 4 (2019) 7773-7783.

[62] G. Keresztury, M.P. Marzocchi, Spectrochimica Acta Part A: Molecular Spectroscopy, 31 (1975) 275280.

[63] K. Nakamoto, Infrared and raman spectra of inorganic and coordination compounds: Part B: Applications in coordination, Organometallic, and Bioinorganic Chemistry, Sixth Edition. 2008, John Wiley \& Sons, Inc, p. 424.

[64]. L. Zhang, S.Q. Li, Ba.W. Sun, D.Z. Liao, Z.H. Jiang, S.P. Yana, G.L. Wang, X.K. Yao, H.G. Wang, Polyhedron 18 (1999) 781-785.

[65] D. Gatteschi, J. Laugier, P. Rey, C. Zanchini, Inorg. Chem. 26 (1987) 938-943,

[66] Y.Y. Lim, R.S. Drago, Inorg. Chem. 11 (1972) 1334-1338.

[67] W. Kanda, M. Nakamura, H. Okawa, S. Kida, Bull. Chem. Soc. Jpn. 55 (1982) 471-476.

[68] A. Jana, S. Mohanta, Inorg. Chim. Acta 405 (2013) 265-273.

[69] S. Bhattacharya, A. Jana, S. Mohanta, Polyhedron 62 (2013) 234-242.

[70] S. Bhattacharya, A. Jana, S. Mohanta, CrystEngComm 15 (2013) 10374-10382.

[71] S. Bhattacharya, A. Jana, M. Fleck, S. Mohanta, Inorg. Chim. Acta 405 (2013) 196-202.

[72] L. Mandal, S. Bhattacharya, S. Mohanta, Inorg. Chim. Acta 406 (2013) 87-94.

[73] T.R. Gordon, R.D. Martyn, Annu. Rev. Phytopathol. 35 (1997) 111-128. 
[74] H. Zine, L.A. Rifai, T. Koussa, F. Bentiss, S. Guesmi, A. Laachir, K. Makroum, M. Belfaiza, M. Faize, Pest Man. Sci. 73 (2017) 188-197.

[75] M. Cherrab, A. Bennani, P.M. Charest, M.N. Serrhini, J. Phytopathol. 150 (2002) 703-709.

[76] S.S. Sangapure, Y. Bodke, B. Raga, Ind. J. Heterocycl. Chem. 11 (2001) 31-37.

[77] A. Tanitame, Y. Oyamada, K. Ofuji, M. Fujimoto, N. Iwai, Y. Hiyama, H. Ito, H. Terauchi, M. Kawasaki, K. Nagai, M. Wachi, J.I. Yamagishi, J. Med. Chem. 47 (2004) 3693-3696.

[78] E.E. Hood, G.L. Helmer, R.T. Fraley, M.D. Chilton, J. Bact. 186 (1986) 1291-1301.

[79] J.M. Young, D.W. Dye, J.F. Bradbury, C.J. Panagopoulos, C.F. Robbs, New Zeal. J. Agr. Res. 21 (1978) 153-177.

[80] C. Morris, C.L. Monteil, O. Berge, Annu. Rev. Phytopathol. 51 (2013) 85-104.

[81] M. Mukesh, S. Prashant, Z. Andleeb, A. Mohd, K.D. Manish, B.P. Chandra, R.S. Upadhyay, Biotechnol. Bioeng. (2019) 181-208. 